\title{
Spider webs as eDNA tool for biodiversity assessment of life's domains
}

Matjaž Gregorič1* , Denis Kutnjak², Katarina Bačnik ${ }^{2,3}$, Cene Gostinčar ${ }^{4,5}$, Anja Pecman², Maja

Ravnikar², Matjaž Kuntner $r^{1,6,7,8}$

${ }^{1}$ Jovan Hadži Institute of Biology, Scientific Research Centre of the Slovenian Academy of Sciences and Arts, Novi trg 2, 1000 Ljubljana, Slovenia

${ }^{2}$ Department of Biotechnology and Systems Biology, National Institute of Biology, Večna pot 111, 1000 Ljubljana, Slovenia

${ }^{3}$ Jožef Stefan International Postgraduate School, Jamova cesta 39, 1000 Ljubljana, Slovenia ${ }^{4}$ Department of Biology, Biotechnical Faculty, University of Ljubljana, Jamnikarjeva ulica 101, 1000 Ljubljana, Slovenia

${ }^{5}$ Lars Bolund Institute of Regenerative Medicine, BGI-Qingdao, Qingdao 266555, China

${ }^{6}$ Department of Organisms and Ecosystems Research, National Institute of Biology, Večna pot 111, 1000 Ljubljana, Slovenia

${ }^{7}$ Department of Entomology, National Museum of Natural History, Smithsonian Institution, 10th and Constitution, NW, Washington, DC 20560-0105, USA

${ }^{8}$ Centre for Behavioural Ecology and Evolution, College of Life Sciences, Hubei University, 368 Youyi Road, Wuhan, Hubei 430062, China

*Corresponding author: Matjaž Gregorič, matjaz.gregoric@zrc-sazu.si, matjaz.gregoric@gmail.com. 


\section{Abstract}

The concept of environmental DNA (eDNA) utilizes nucleic acids of organisms directly from the environment. Recent breakthrough studies have successfully detected a wide spectrum of prokaryotic and eukaryotic eDNA from a variety of environments, ranging from ancient to modern, and from terrestrial to aquatic. These numerous sources promise to establish eDNA as a tool for diverse scientific settings. Here, we propose and establish spider webs as a source of eDNA with far reaching implications. First, we conducted a field study to track specific arthropod targets from different spider webs. We then employed high-throughput amplicon sequencing of taxonomic barcodes to investigate the utility of spider web eDNA for biodiversity monitoring of animals, fungi and bacteria. Our results show that genetic remains on spider webs allow the detection of even the smallest target organisms. We also demonstrate that eDNA from spider webs is useful in research of community compositions in different domains of life, with potentially highly detailed temporal and spatial information.

Keywords: Environmental DNA, metabarcoding, microbial communities, biodiversity monitoring 


\section{Introduction}

The continuous loss of biodiversity is among the critical societal challenges ${ }^{1-3}$. Biodiversity data, crucial to countering these trends, still mostly rely on traditional taxonomic species identification, such as morphological and behavioral species-diagnostic traits. These traditional methods have wellknown shortcomings, e.g. the majority of biodiversity is undescribed ${ }^{4,5}$, phenotypic diagnoses are often insufficient ${ }^{6}$, and crucial taxonomic expertise is declining ${ }^{7,8}$. As a result, traditional approaches to conducting efficient and standardized biodiversity surveys are often inadequate. In addition, traditional sampling techniques are invasive. They are likely to kill the target organisms and may further harm their ecosystems ${ }^{3,9}$.

Novel molecular approaches, such as sampling of environmental DNA (eDNA), i.e. obtaining intra- or extracellular genetic material directly from environmental samples, has the potential to overcome many limitations of traditional biodiversity monitoring ${ }^{3,10-12}$. eDNA is present in all media, e.g. soil, sediment, water and permafrost, and depending on the medium, the preservation of eDNA varies from a few weeks to hundreds of thousands of years ${ }^{3,13,14}$. eDNA can be detected either using targeted tests within a single-species approach, or using generic high-throughput sequencing in a multiple-species approach, e.g., by DNA metabarcoding ${ }^{15}$. Accordingly, eDNA is increasingly used to address fundamental questions in basic and applied research fields such as ecology, molecular biology, nature conservation, and paleontology ${ }^{3,11,16-18}$. Recent studies using eDNA have assessed plant $^{18,19}$, fungal ${ }^{20,21}$, earthworm ${ }^{22}$, amphibian ${ }^{23}$ and fish ${ }^{24}$ communities, characterized the functional potential of microbial and viral communities ${ }^{25}$, monitored invasive species ${ }^{52,53}$, and detected difficultto-find species such as cave olms ${ }^{26}$, brown bears ${ }^{27}$ and whale sharks ${ }^{28}$.

In this paper, we argue that spider webs represent a powerful tool for obtaining eDNA. Spiders are among the dominant predators of arthropod communities ${ }^{29}$. Not all spiders construct capture webs, 
but those that do, show enormous diversity and ecological abundance. Their webs range from millimeters to meters in size, are diverse in architecture, in the type of silk they consist of, and in the microhabitat they are suspended in ${ }^{19,20}$. Spider webs are ubiquitous in both natural and anthropogenic ecosystems. Their potential use as a source of eDNA has been proposed only recently. One pioneering study in controlled laboratory conditions demonstrated that widow spider webs contain genetic traces of the host and its single prey ${ }^{30}$. Another preliminary study confirmed these findings by amplifying spider DNA from silk of two host species ${ }^{31}$. Recently, a metabarcoding study demonstrated that spider webs are passive aerial filters, and thus potentially represent a useful new source of eDNA ${ }^{32}$. However, these early studies have limitations (see Supplementary material 1 ) and we believe that the utility of eDNA from spider webs far surpasses simple identification of spiders and their prey.

To move towards a methodology that utilizes spider webs as a source of eDNA, we need to advance our understanding of two critical issues. The first revolves around a single species detection in a web. This is achieved by testing the performance of species-specific detection of eDNA from spider webs over a wide dynamic range of concentrations of the target's DNA, and including the establishment of appropriate DNA isolation and amplification controls. The second issue is whether webs, as aerial filters, can be used to identify multiple organisms. Given that temporal and spatial factors affect spider web biology, comparative metabarcoding should yield sufficient variation in species composition, as well as abundances, for biodiversity estimations. For example, many spider species build webs in specific microhabitats, which could provide fine spatial information. Also, orb web spiders completely renew their webs daily, while webs of other spider families are long-lasting ${ }^{33}$, which can provide useful temporal information. Furthermore, some but not all spider webs contain capture threads that are coated in viscous glue (e.g. orb webs) $)^{34}$, and could thus function differently in accumulating genetic material compared to webs that only contain "bare" silk threads (e.g. sheet webs). 
Here, we employ the single- and multi-species approaches to estimate the utility of eDNA from spider webs. Within our single-species approach, we conduct field tests and apply rigorous laboratory protocols to test whether model prey can be detected from spider webs. These tests use quantitative PCR (qPCR) to detect prey DNA in the webs of the garden spider Araneus diadematus and the common hammock-weaver Linyphia triangularis, two species with different web types. Our multi-species approach then establishes metabarcoding protocols. In order to investigate how eDNA from spider webs may be used for biodiversity monitoring, we sampled webs of the above spider species in two distinct forest types and in two subsequent years. The detected animal, fungal, and bacterial diversities strongly support our prediction that eDNA accumulated in spider webs contains important biodiversity information.

\section{Methods}

\section{Single-species eDNA detection}

In a forest in Slovenia, we selected five webs of both the garden spider Araneus diadematus and the common hammock-weaver Linyphia triangularis. The garden spider builds a typical two-dimensional orb web, consisting of non-sticky, as well as sticky threads ${ }^{34}$. The viscous glue of these sticky capture threads is among the best bio-adhesives known ${ }^{35}$, likely making orb webs efficient in capturing parts of impacting arthropods and airborne particles. The common hammock-weaver builds a threedimensional web, consisting of a hammock-like segment, interlaced with a looser mesh of silk above and below it. These webs do not contain sticky capture threads ${ }^{34}$. We introduced two small sized house crickets Acheta domestica ( $5 \mathrm{mg}$ body mass) into each web. We then collected the webs several hours later. The collected silk contained no visible prey remains. We collected additional five webs of each spider species as control samples. We collected each web onto the tip of a sterile 
plastic inoculation loop, breaking the loop off into a sterile microcentrifuge tube immediately after collection. For further processing, we stored all web samples at $-80^{\circ} \mathrm{C}$.

We isolated DNA from all samples using an adapted protocol of the PowerLyzer PowerSoil DNA Isolation Kit (Qiagen, USA; Supplementary material 2). We used quantitative (q)PCR that enables sensitive detection and quantification compared to regular PCR. In order to test the detection of house crickets in web samples, we designed and tested two TaqMan chemistry based assays targeting $102 \mathrm{bp}$ and $127 \mathrm{bp}$ fragments of the mitochondrial gene cytochrome c oxidase subunit I, respectively (COI; Supplementary material 2 , Table S1). We provide amplification protocols in Supplementary material 2 .

Throughout laboratory work, we employed rigorous protocol controls (Table 1): a negative isolation control, a positive amplification control, no template control during qPCR amplification, and an internal control of the DNA isolation process (using the "Eukaryotic 18S rRNA Endogenous Control", Applied Biosystems, USA). To control for the performance of the two designed assays for detection of A. domestica, we employed further controls that we performed on two web types, using laboratory populations of the orb web building African hermit spider (Nephilingis cruentata) and the cobweb building Mediterranean black widow (Latrodectus tredecimguttatus). We tested the assays for DNA isolated from webs only (negative control) and from target (house cricket) tissue only (positive control). We employed assay specificity controls by testing the amplification of the host (spider) and non-target prey (mealworms) DNA. To control for potential inhibitors in the amplification matrix (spider silk), we tested the assays on samples of target tissue with added spider silk. To test the dynamic range of the assays, we tested both assays on a range of target DNA concentrations, by performing a dilution series of our test samples' (webs of both species that were fed with house cricket) DNA in nuclease free water, from $10^{-1}$ to $10^{-9}$. 
We considered a sample positive if it produced an exponential amplification curve that was distinguishable from the negative controls. In such cases, we determined the quantification cycles (Cq). For fluorescence acquisition and determination of Cq, we used the SDS 2.4 software (Applied Biosystems, USA). For this, we set the baseline between the 3rd and the 8th amplification cycle, and we set the fluorescence threshold manually at 0.05 , i.e. at a level that was above the baseline and sufficiently low to be within the exponential increase region of the amplification curve.

\section{DNA metabarcoding}

We sampled two forests in Slovenia from different climates, one submediterranean, the other continental. In both, the above described spider species A. diadematus and L. triangularis co-occur in close proximity. In each forest, we collected five webs of each species, as described in the "Singlespecies eDNA detection". In the submediterranean forest, we repeated the sampling of $L$. triangularis webs in two subsequent years (25 samples in total, see Supplementary material 2, Table S6).

We isolated DNA from all samples using an adapted protocol of the PowerLyzer PowerSoil DNA Isolation Kit (Qiagen, USA; Supplementary material 2). As isolations for all web samples were successful, we randomly chose five web samples per web type per forest per year ( 25 samples total) for amplification. We amplified DNA from samples using primers commonly used in metabarcoding studies of arthropods, fungi and bacteria. For amplification of animal DNA, we used the primer set mICOlintF and jgHCO2198 that target a $313 \mathrm{bp}$ fragment of the mitochondrial gene cytochrome $\mathrm{c}$ oxidase subunit I $(\mathrm{COI})^{36}$. For amplification of fungal DNA, we used the primer set ITS3_KYO2 and ITS4 that target a 300-400 bp fragment of the Internal transcribed spacer (ITS) ${ }^{37}$. For amplification of bacterial DNA, we used the primer pair S-D-Bact-0341-b-S-17 and S-D-Bact-0785-a-A-21 that targets a 464 bp fragment of 165 ribosomal RNA $(16 S)^{38}$. We provide other primer details and the amplification protocol in Supplementary material 2. 
For all samples, we performed high-throughput sequencing of the amplicons using the Illumina MiSeq sequencing platform, through a commercial provider. Before sample submission, we measured the amount of amplified DNA for all samples, using microfluidic capillary electrophoresis on the Labchip GX (PerkinElmer), where we used the DNA High Sensitivity Assay. Based on these DNA amplicon amounts, we sequenced bacterial amplicons separately, as the amount of amplified bacterial DNA was several-fold larger compared to that of fungi and animals. For sequencing, we pooled amplified DNA of fungi and animals in a ratio of 3:1, as we expected more fungal OTUs compared to animal ones.

In all parts of sample preparation and sequencing, we included four negative control samples, obtained from individual DNA isolation procedures, and a microbial mock community sample ("ZymoBIOMICS Microbial Community Standard", Zymo Research, Germany) that we used as a positive control in the metabarcoding experiment.

We analyzed sequence data using the QIIME2 2019.4 software package (Quantitative Insights Into Microbial Ecology $)^{39}$. We trimmed primers, adapters, and regions with the quality score $<20$. Since the assembly of the paired end reads was not optimal, we used only single-end forward reads for analysis. We denoised the reads using DADA2, aligned representative sequences using mafft, and constructed the midpoint-rooted tree using FastTree. We calculated alpha and beta diversity indices. We used trained feature classifier to assign the sequences to taxonomic categories using three databases: Silva release 132 (bacteria) ${ }^{40}$, dynamically clustered UNITE ITS database version 8.0 (fungi) $^{41}$, and BOLD downloaded on 31. 7. 2019 (animals) ${ }^{42}$. Since BOLD database is not provided in a format directly useful in QIIME2 and downloading of the complete database was not possible, we downloaded the fasta and tsv files using custom scripts for 238 smaller taxonomic groups, which contained sufficiently few data to result in successful download and later concatenation into a 
complete database covering all taxa present in BOLD. We concatenated these files and retained only sequences with 'COI-3P' or 'COI-5P' in the name. We replaced all characters not in the IUPAC nucleotide code with Ns. To produce the final set of sequences for use in QIIME2, we dereplicated the database with 'vsearch' using a threshold of $0.97^{43}$. We used alignment to the ITS and COI databases to separate ITS and COI sequences, which were pooled before sequencing - we discarded all non-aligning sequences (at the $90 \%$ cutoffs for the aligning parts of the sequence and the total sequence) using the option 'qiime quality-control exclude-seqs'. Due to the large number of nonanimal DNA in the COI sequences, we manually identified the representative sequences by blasting them against all barcode records on the BOLD database. We then manually removed all non-animal representative sequences from the QIIME2 representative sequences file, which was finally used to filter the feature table with the option 'qiime feature-table filter-features'.

To render our samples comparable for diversity analyses, we randomly sampled reads from each sample and thus equalized their size. We retained 15900 reads for bacterial, 1360 reads for fungal, and 490 reads for animal samples, maximizing the number of samples rather than the number of reads (Supplementary material 2, Table S7). To investigate alpha diversity, we calculated the Chao1 and Shannon indices. We assessed differences in alpha diversity compositions using the KruskalWallis $\mathrm{H}$ test. We determined the distance and dissimilarity matrices, to visualize the ordination and clustering of the bacterial, fungal and animal community compositions for beta diversity analyses, through weighted and unweighted Unifrac distance metrics ${ }^{44}$, and with the Jaccard similarity coefficient and Bray-Curtis dissimilarity. We evaluated the ordination patterns based on phylogenetic distance metrics using principal coordinate analysis (PCOA). We assessed differences in community compositions between sample types by non-parametric permutational analysis of variance (PERMANOVA), using the unweighted UniFrac distance metric and other settings at default within the QIIME2 pipeline. 


\section{Results}

To test the performance of the two assays designed for detection of $A$. domestica, we employed negative controls, primer specificity controls, and amplification controls. Both primer sets were positive for the house cricket (Table 1). In the dilution series, both primer sets showed consistent detection of a wide range of target DNA concentrations, with Adom1 primers consistently outperforming the Adom2 primers, i.e. having lower Cq values for the same samples (Fig. 1a, Table 1). Therefore, we used Adom 1 in field tests. We successfully traced house crickets in all 10 webs, with Cq values ranging from 14 to 32 (Fig. 1b). We also successfully traced house crickets in all 10 samples when diluted 10 -fold. All negative controls were negative, while the internal isolation control (18S assay) was positive in all samples.

Our metabarcoding investigation retrieved a total of 2,164,380 bacterial reads, 721,594 fungal reads, and 174,006 animal reads from the 25 web samples. Summing up to 11,285 OTUs, bacteria represented the largest diversity, followed by fungi with 4005 OTUs, and animals with 314 OTUs (Supplementary material 3, Tables S1, S2, S4). Among bacteria, we identified 30 phyla (Supplementary material 3, Table S1). Among fungi, we identified 9 phyla, containing 31 classes, 108 orders and 307 families. Ascomycota and Basidiomycota were by far the most diverse, encompassing 297 of these 307 families (Supplementary material 3, Table S3). Among animals, we identified 3 phyla, containing 5 classes, 16 orders and 50 families. Insects were the most diverse, representing 33 of these 50 families (Supplementary material 3, Table S5). The microbial mock community sample that we used as control contained eight bacterial and two fungal species, of which we detected all but one bacterial species.

The statistical analysis of the chao1 index of alpha diversity showed that in the two forests, webs accumulate an equal diversity of bacterial $(p=0.950, H=0.004)$, fungal $(p=0.412, H=0.672)$ and 
animal ( $p=0.143, H=2.148$ ) eDNA (Fig. 2 ). The sampling year yielded a similar eDNA diversity of the three organismal groups (bacteria: $p=0.314, H=1.016$; fungi: $p=0.456, H=0.556$; animals: $p=$ $0.207, H=1.595)$. Compared to orb webs, sheet webs accumulated a higher diversity of bacterial $(p=$ $0.014, H=6.036)$ and fungal $(p=0.022, H=5.270)$, but not animal $(p=0.518, H=0.418)$ eDNA. The statistical analysis of the Shannon index of alpha diversity showed similar results (Supplementary material 3). The described diversity pattern was reflected in the average OTU number per web (Supplementary material 3, Fig. S1). The different biology of the two web types was reflected in the taxonomic representation of taxa on sheet versus orb webs. For example, no orb webs contained nematodes or rotifers, while $20 \%$ of sheet webs contained nematodes and $65 \%$ contained rotifers. Similarly, of the nine insect orders, all were found on sheet webs, but only four on orb webs. Detailed results of OTU and taxonomic representations are accessible in Supplementary materials 3 and original data in Supplementary material 4.

Sampling locality, web type, and sampling time all affected the inferred beta diversities (community composition) of bacteria (web type: $p=0.006, F=1.48165$; locality: $p=0.003, F=1.52083$; year: $p=$ $0.011, F=1.37463$ ), fungi (web type: $p=0.001, F=5.73776$; locality: $p=0.013, F=2.0729$; year: $p=$ $0.001, F=3.86025$ ) and animals (web type: $p=0.008, F=1.83303$; locality: $p=0.001, F=3.27745$; year: $p=0.007, F=1.7966)$. The PCoA plots visualize differences community compositions, and both indices using presence/absence information only (unweighted Unifrac, Jaccard index), as well as those incorporating abundance data (weighted Unifrac, Bray-Curtis coefficient), show similar results (Fig. 3; Supplementary material 3, Fig. S2).

\section{Discussion}

Spider webs prove suitable for detecting genetic traces of organisms in both a targeted search of a specific species and within a metabarcoding approach. We successfully trace prey introduced into 
spider webs and show that the targeted search for eDNA from individuals of a single species is a valid concept. In addition, we show that spider webs act as passive filters of the air column by accumulating genetic traces of diverse organisms. These results suggest spider webs are a promising tool for general biodiversity monitoring through DNA metabarcoding.

The idea of using organisms and their extended phenotypes, such as spiders and their webs, to sample genetic material of other local organisms, parallels recent studies using bloodsucking insects to identify the local fauna. For example, mosquito blood had traces of their avian, mammalian and amphibian hosts ${ }^{45}$, tick blood was used to identify their rodent and stoat hosts ${ }^{46}$, blood from leeches identified a range of mammalian species ${ }^{47}$, and carrion flies successfully identified diverse mammals ${ }^{48}$. Similarly, the contents of spider intestines can assess local arthropod biodiversity ${ }^{49}$. By accumulating DNA of the hosts' prey, spider webs resemble the intestine contents of bloodsucking and predatory invertebrates. However, spiders are generalist predators, and furthermore their webs are passive traps ${ }^{34}$. We therefore expected that spider webs would accumulate a more general sample of organisms compared to intestine contents. Showing that spider webs efficiently capture diverse "aerial plankton" from all domains of life, our results support this expectation.

\section{Single-species eDNA detection}

Our tests used two spider species that construct different webs. The capture threads of the hammock web are dry, while the garden spider's classical orb contains glue-coated spirals. Although this would intuitively suggest more prey detection in the gluey web, this was not the case. The equally successful detection of prey in all our samples (Fig. 1b) rather indicates that even the smallest traces of arthropods in webs allow for successful amplification. Furthermore, our approach allows the tracing of DNA of even the smallest-bodied arthropods. Having fed spiders 5 mg crickets, we used 
a size class below which potential prey is often ignored due to low nutritional value ${ }^{50-53}$. Both these arthropod "leftovers", as well as larger prey are thus expected to be easily detected.

Since spiders tend to cut fallen debris out of their webs, but usually ignore the presence of small, dust-like particles such as plant pollen, fungal spores, and bacteria, these organisms should also be detectable as single-species eDNA in spider webs. While each spider web in our experiments represented a single sample, future studies could pool several webs in a habitat of interest, thereby even increasing the detection power of such approach.

\section{DNA metabarcoding}

A good eDNA tool for assessing local biodiversity should result in beta diversity reflecting differences in sample types and sample collection. Our results show that forest type (sub-mediterranean versus continental), time of collection (same season in two consecutive years), and web type (sticky and rebuilt daily versus non-sticky and long-lasting) all affect the recovered beta diversity of animal, fungal and bacterial communities. Thus, the information obtained from a few individual webs appears to be sufficient to show differences in community compositions among and even within habitats (i.e. among web types). The differentiation of samples based on web type, locality and year is particularly pronounced for fungal communities (Fig. 4). This result is in accordance with the research on fungal communities of soil samples, where metabarcoding of fungal taxa has high discrimination power ${ }^{54}$. Similarly, the airborne microbiomes fluctuate in time and space, and our data thus likely reflects actual differences rather than stochastic variability ${ }^{55,56}$. Thus, in particular, our results indicate that eDNA from spider webs could be useful in tracking biodiversity in time and space. For example, using a general sampling of spider webs, general biodiversity monitoring could be carried out throughout a season or over several years. On the other hand, by sampling spider 
webs in specific microhabitats, i.e. vegetation layers, useful spatial information could be brought into research of community compositions.

\section{Utility of eDNA from spider webs}

When using eDNA to draw conclusions about the proximity of organisms relative to the traces of their DNA, it is crucial to also consider the spatial and temporal distribution and persistence of eDNA. For example, traces of genetic material remain in water for up to several weeks, but can persist for decades or even hundreds of thousands of years in soil or in permafrost ${ }^{3,13,14}$. The fast degradation of DNA in aquatic ecosystems makes eDNA useful in addressing topics like nature conservation, where positive detection reflects the contemporary presence of species and populations. However, in aquatic eDNA samples, the release of older genetic material from bottom sediments and the transport of eDNA in flowing and marine waters are potential sources of contamination ${ }^{3,9}$. Similar to aquatic ecosystems, eDNA collected from the air column via spider webs represents a contemporary presence of organisms in the environment, with potentially more accurate spatial and temporal information. Also, we find temporal contaminations unlikely. For example, some web types (e.g. sheet webs) are suspended for several weeks or even months, while most orb webs are rebuilt daily $^{33,34}$. In addition, many spider species choose web-specific microhabitats ${ }^{34}$. While further studies are needed to elucidate the degeneration rate of genetic traces on longer lasting spider webs, it is clear that spider webs are not only a new tool for "filtering out" genetic material from the air column, but are also unique in the precise spatial and temporal information they provide.

In a straight forward application, eDNA from spider webs could provide a non-invasive and simple method for identifying juvenile spider specimens that cannot be determined morphologically, and could lead to new ways of studying interactions between spiders and their prey without the laborintensive and biased sampling of potential target prey ${ }^{30}$. However, our results show a much broader 
utility of eDNA from spider webs. For example, webs could be used to address questions related to entire communities, such as the distribution and composition of arthropods, plants, fungi and bacteria over seasons and years, habitats, etc. Immediate applications in nature conservation are also foreseeable, examples being the assessment of declining global insect biodiversity ${ }^{57-59}$. More precisely, the development of a general pollinator eDNA sampling approach could be used as an information platform to counter the concerning, global pollinator declines exacerbated by the lack of taxonomic expertise ${ }^{60}$. Indeed, among the high diversity of taxa encountered in our web samples, we found several pollinator species such as bees, flies, wasps and beetles, and including the endangered longhorn beetles (Supplementary material 3). In addition to tracking pollinators and endangered species, eDNA from spider webs could also be used to track invasive or pathogen-carrying mosquitoes ${ }^{61}$, perhaps as an alternative to direct sampling of water puddles. Furthermore, our results indicate that eDNA from spider webs could be used to investigate species associations. For example, we found co-occurring taxa that are in known relationships, both parasitic and mutualistic (Supplementary material 3).

In our samples, we found several animal, fungal and bacterial taxa that are of agricultural and medical importance to humans (Supplementary material 3), which highlights a range of possible uses of eDNA from spider webs. Notable examples among plant pathogens and disease-causing agents are genera that include grain rust and wheat curl mites (Eriophyidae) ${ }^{62,63}$, gall and fungus gnats (Cecidomyiidae, Sciaridae) ${ }^{64,65}$, aphids (e.g. Pineus and Anoecia) ${ }^{66-68}$, several fungal representatives that damage wheat crops (e.g. Fusarium and Ustilago $)^{69-71}$, eudicot plants $(\text { Verticillium })^{72}$, and rice (Magnaporthe grisea $)^{73}$, as well as several bacterial genera that include plant pathogenic representatives, e.g. Pseudomonas, Erwinia, Dickea, and Pectobacterium ${ }^{74}$. Therefore, spider web eDNA could be used for early detection of agricultural pests, even in the absence of disease symptoms, an approach already demonstrated for eDNA from orchards ${ }^{75-77}$. Moreover, we found several medically important fungal and bacterial representatives, many of which cause respiratory 
problems and allergies (e.g. Aspergillus, Stachybotrys and Botrytis) ${ }^{78-80}$, food spoilage and gastrointestinal infections (e.g. Absidia) ${ }^{81}$, or are associated with livestock (Salmonella and Clostridium) $^{82}$ and invertebrate vectors (e.g. Haemophilus) ${ }^{83,84}$. Perhaps, future use of eDNA from spider webs can extend our understanding about the presence and role of human pathogens in nonurban environments.

\section{Concluding remarks}

Spider webs are passive air filters. Utilizing them as an eDNA source thus represents a novel technique for sampling air masses, an approach equivalent to sampling other media such as water, ice, and sediments. Our results show that spider webs can become a new tool for the targeted tracking and general monitoring of any kind of organisms, from arthropods, rotifers and fungi, to bacteria, plants and perhaps viruses. As such, the use of eDNA from spider webs offers numerous potential applications from biodiversity monitoring, tracking invasive and pest species, animal diet assessment, obtaining climate change data, to studies on the distribution and niches of arthropods, plants, fungi and bacteria, whether in a single species or in a metabarcoding context. 


\section{Figures}
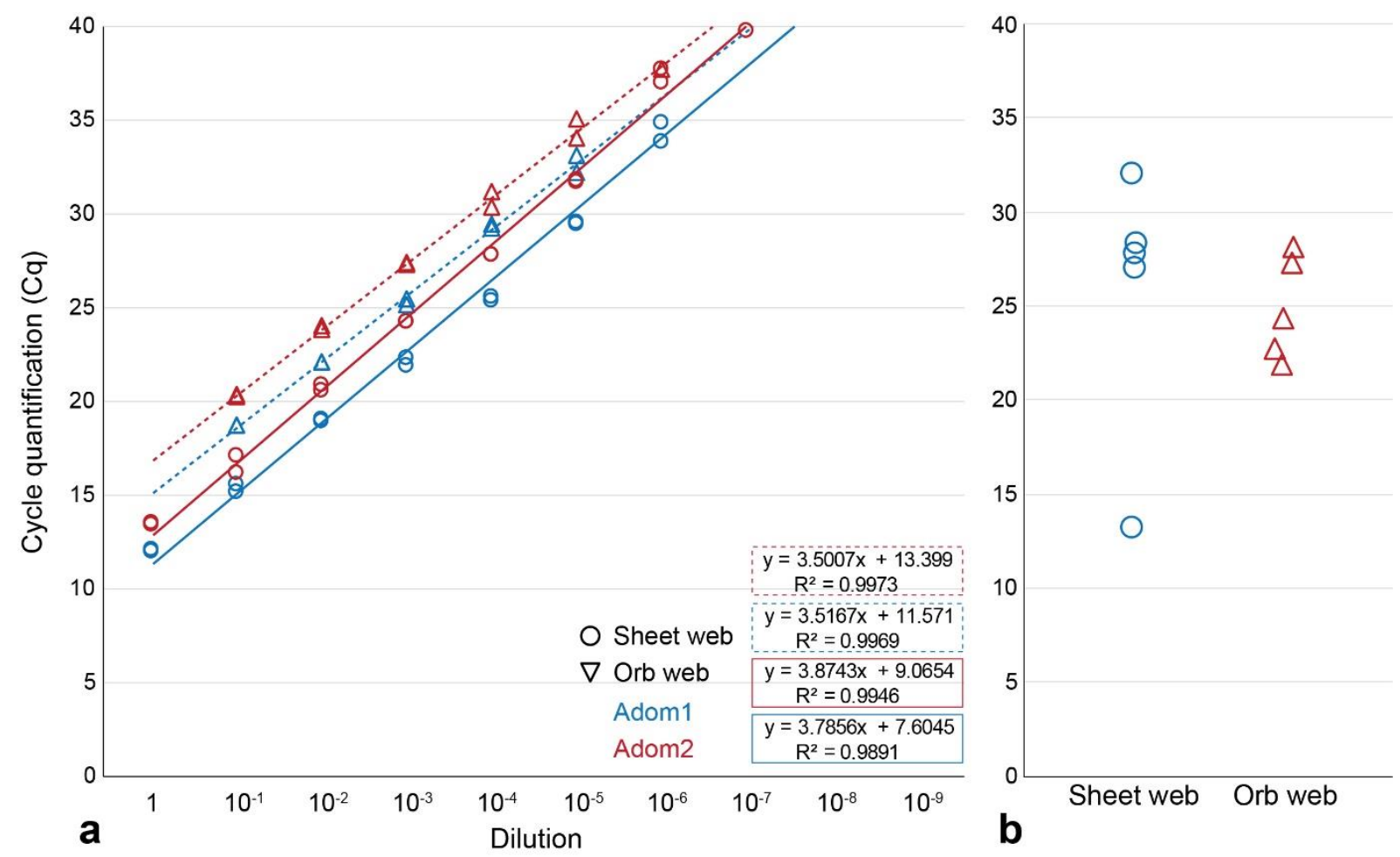

Figure 1: Targeted detection of house crickets from webs in nature. a) The dilution series of DNA isolated from two web types (designated by architecture) containing traces of prey sample (Acheta domestica) performed usingthe Adom1 and Adom2 qPCR assays (designated by color). a) Detection success of the target, showing the Cq values for Adom1 for samples of two web types containing traces of $A$. domestica DNA.
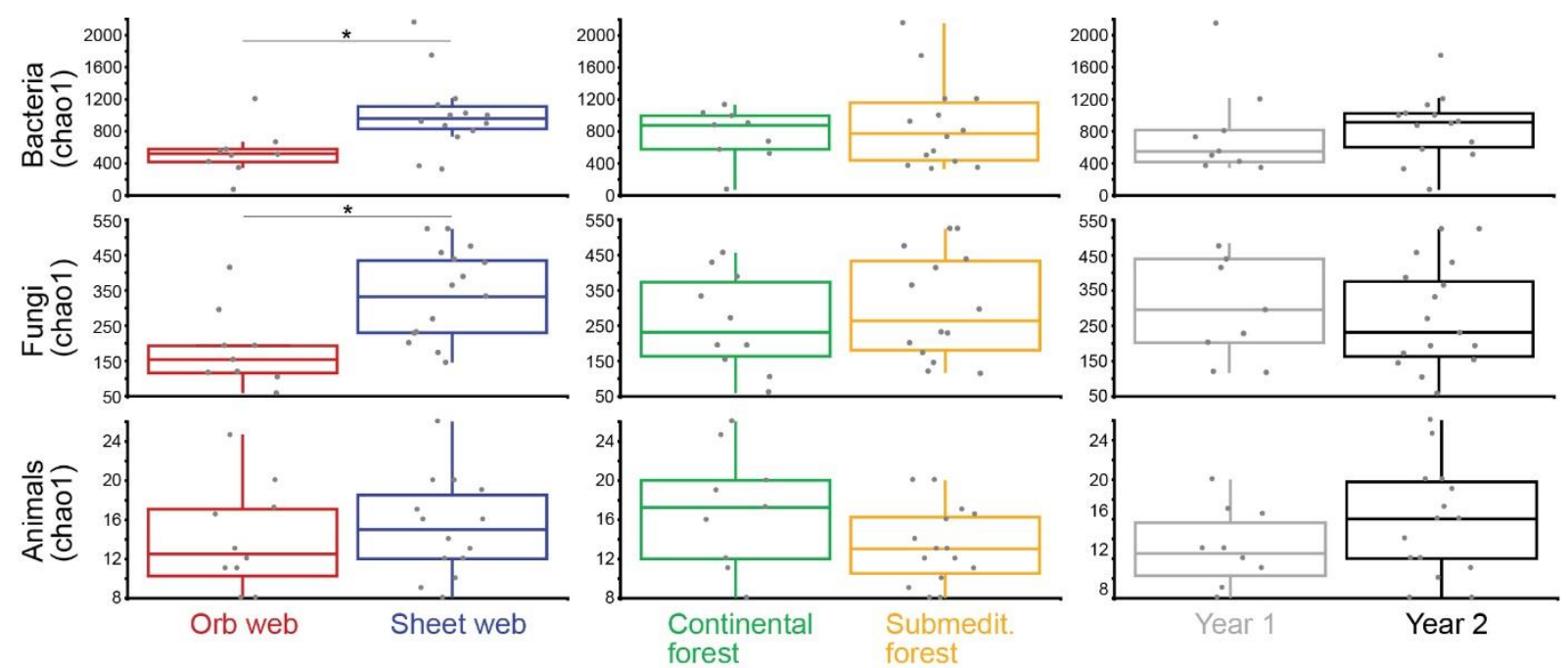
Figure 2: The alpha diversities of bacteria, fungi and animals, inferred from spider web eDNA using a

DNA metabarcoding approach, and compared between web types (a), forests (b) and years sampled (c). Asterisks mark statistically significant differences.

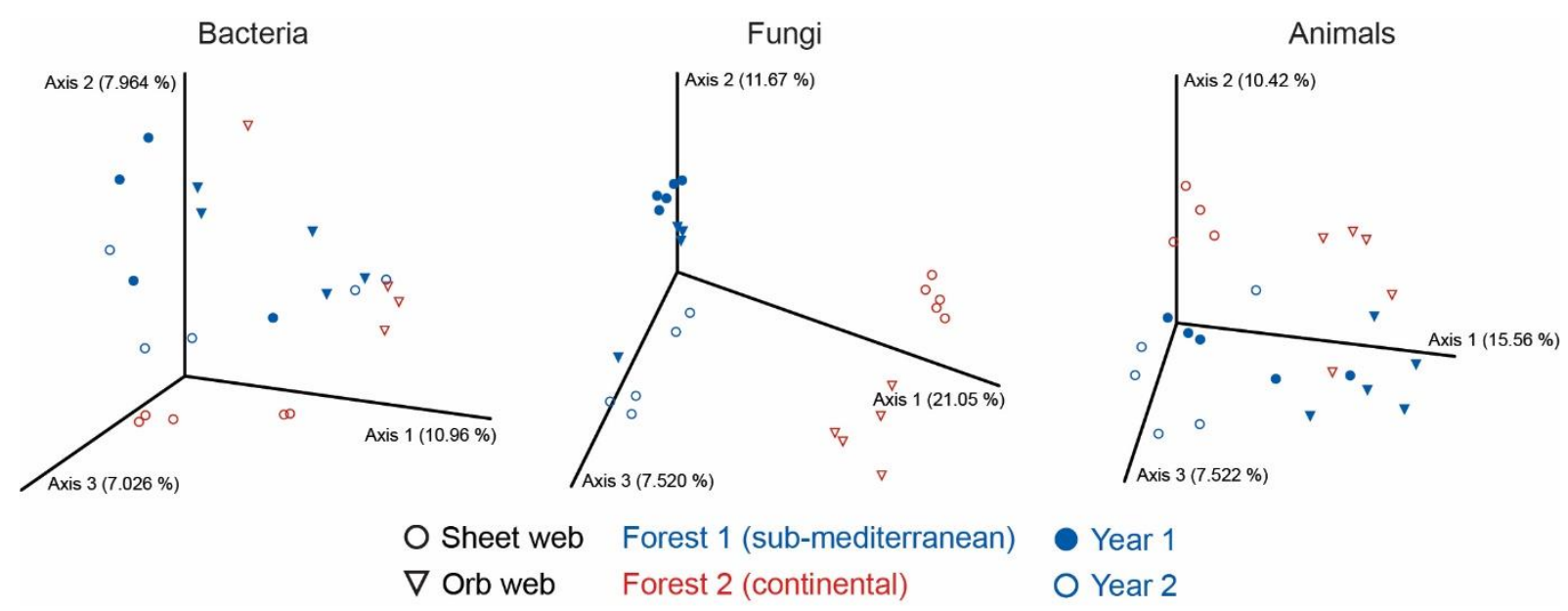

Figure 3: The beta diversities (community composition) of bacteria, fungi, and animals, inferred from spider web eDNA using a DNA metabarcoding approach. The PCoA plots visualize the beta diversities estimated using the unweighted Unifrac distance metric.

\section{Tables}

Table 1: Controls used for testing the performance of the qPCR assays used for the detection of $A$. domestica.

\begin{tabular}{llllll} 
& & \multicolumn{2}{l}{ Adom1 (Cq) } & \multicolumn{2}{c}{ Adom2 (Cq) } \\
Sample type & Control type & Undil. & 10x dil. & Undil. & 10x dil. \\
\hline Cobweb, no target & Negative, primer specificity & neg. & neg. & neg. & neg. \\
Orb web, no target & Negative, primer specificity & neg. & neg. & neg. & neg. \\
Web host tissue (widow spider) & Primer specificity & neg. & neg. & neg. & neg. \\
Web host tissue (hermit spider) & Primer specificity & neg. & neg. & neg. & neg. \\
Laboratory prey (mealworm) & Primer specificity & neg. & neg. & neg. & neg. \\
Target (house cricket) & Primer specificity & 11.96 & 18.06 & 12.99 & 19.56 \\
Fresh cobweb + target tissue & Amplification inhibition & 12.31 & 18.87 & 13.30 & 20.39 \\
Fresh orb web + target tissue & Amplification inhibition & 15.09 & 22.01 & 16.33 & 23.49 \\
Cobweb from spider fed with target & Positive & 23.88 & 29.73 & 25.88 & 31.50 \\
Orb web from spider fed with target & Positive & 17.35 & 23.93 & 18.73 & 25.69
\end{tabular}




\section{Supplementary material}

Supplementary material 1: Additional literature overview.

Supplementary material 2: Additional methods: DNA isolation protocol, primer details and amplification protocols.

Supplementary material 3: Additional metabarcoding results: alpha and beta diversity results, and comments on taxa of human interest.

Supplementary material 4: QIIME2 output files (view at https://view.qiime2.org/ or unzip for raw data).

\section{Acknowledgements}

We thank the technical and student staff at the Department of Biotechnology and Systems Biology, National Institute of Biology, for their logistic and technical help in the laboratory. We thank S. Koren and Omega d.o.o. for their help with the microfluidic capillary electrophoresis. This study was funded by the following grants from the Slovenian Research Agency: Z1-8143, P1-0236, P4-0407, P1-0198, P1-0255, J1-9163 and J1-1703.

\section{Author contributions}

M.G., M.K., D.K., and M.R. conceived the study. M.G., K.B., A.P., and C.G. performed experiments and analyses. All authors jointly wrote the paper. 


\section{Competing interests}

The authors declare no competing interests.

\section{Data availability}

All experimental data are available in the manuscript and supplementary material 4.

\section{References}

1 Waters, C. N. et al. The Anthropocene is functionally and stratigraphically distinct from the Holocene. Science 351, aad2622 (2016).

2 Ceballos, G. et al. Accelerated modern human-induced species losses: Entering the sixth mass extinction. Science Adv 1 (2015).

3 Thomsen, P. F. \& Willerslev, E. Environmental DNA - An emerging tool in conservation for monitoring past and present biodiversity. Biol Conserv 183, 4-18 (2015).

$4 \quad$ May, R. M. How many species inhabit the Earth. Sci Am 267, 42-48 (1992).

5 Mora, C., Tittensor, D. P., Adl, S., Simpson, A. G. B. \& Worm, B. How many species are there on Earth and in the ocean? Plos Biology 9 (2011).

6 Coddington, J. A. \& Levi, H. W. Systematics and evolution of spiders (Araneae). Annu Rev Ecol Syst 22, 565-592 (1991).

7 Hopkins, G. W. \& Freckleton, R. P. Declines in the numbers of amateur and professional taxonomists: implications for conservation. Anim Conserv 5, 245-249 (2002).

8 Wheeler, Q. D., Raven, P. H. \& Wilson, E. O. Taxonomy: Impediment or expedient? Science 303, 285-285 (2004). 
9 Goldberg, C. S., Strickler, K. M. \& Pilliod, D. S. Moving environmental DNA methods from concept to practice for monitoring aquatic macroorganisms. Biol Conserv 183, 1-3 (2015). Baird, D. J. \& Hajibabaei, M. Biomonitoring 2.0: a new paradigm in ecosystem assessment made possible by next-generation DNA sequencing. Mol Ecol 21, 2039-2044 (2012). plant communities. Mol Ecol 26, 5872-5895 (2017). and monitoring. (Oxford University Press, 2018).

13 Dejean, T. et al. Persistence of Environmental DNA in Freshwater Ecosystems. Plos One 6 (2011).

14 Willerslev, E. et al. Fifty thousand years of Arctic vegetation and megafaunal diet. Nature $506,47-+(2014)$.

$15 \mathrm{Ji}$, Y. et al. Reliable, verifiable and efficient monitoring of biodiversity via metabarcoding. Ecol Lett 16, 1245-1257 (2013).

16 Taberlet, P., Coissac, E., Hajibabaei, M. \& Rieseberg, L. H. Environmental DNA. Mol Ecol 21, 1789-1793 (2012).

17 Taberlet, P., Coissac, E., Pompanon, F., Brochmann, C. \& Willerslev, E. Towards nextgeneration biodiversity assessment using DNA metabarcoding. Mol Ecol 21, 2045-2050 (2012).

18 Taberlet, P. et al. Soil sampling and isolation of extracellular DNA from large amount of starting material suitable for metabarcoding studies. Mol Ecol 21, 1816-1820 (2012). Yoccoz, N. G. et al. DNA from soil mirrors plant taxonomic and growth form diversity. Mol Ecol 21, 3647-3655 (2012).

20 Buee, M. et al. 454 Pyrosequencing analyses of forest soils reveal an unexpectedly high fungal diversity. New Phytol 184, 449-456 (2009). 
21 O'Brien, H. E., Parrent, J. L., Jackson, J. A., Moncalvo, J. M. \& Vilgalys, R. Fungal community analysis by large-scale sequencing of environmental samples. Appl Environ Microb 71, 55445550 (2005).

22 Bienert, F. et al. Tracking earthworm communities from soil DNA. Mol Ecol 21, 2017-2030 (2012).

23 Pilliod, D. S., Goldberg, C. S., Arkle, R. S. \& Waits, L. P. Estimating occupancy and abundance of stream amphibians using environmental DNA from filtered water samples. Can J Fish Aquat Sci 70, 1123-1130 (2013).

24 Thomsen, P. F. et al. Monitoring endangered freshwater biodiversity using environmental DNA. Mol Ecol 21, 2565-2573 (2012).

25 Dinsdale, E. A. et al. Functional metagenomic profiling of nine biomes. Nature 452, 629-632 (2008).

26 Gorički, Š., Stanković, D., Năpăruș-Aljančič, M., Snoj, A. \& Aljančič, G. Searching for black Proteus (Proteus anguinus parkelj) in karst groundwater with the help of eDNA. 2016 International Conference on Subterranean Biology, 13 - 17 June 2016, 31 (2016).

27 Skrbinšek, T. et al. Monitoring the effective population size of a brown bear (Ursus arctos) population using new single-sample approaches. Mol Ecol 21, 862-875 (2012).

28 Sigsgaard, E. E. et al. Population characteristics of a large whale shark aggregation inferred from seawater environmental DNA. Nature Ecol Evol 1, 0004 (2016).

29 Coddington, J. A. \& Colwell, R. K. in Encyclopedia of Biodiversity Vol. 1, 199-218 (Academic Press, Elsevier, 2000).

30 Xu, C. C. Y., Yen, I. J., Bowman, D. \& Turner, C. R. Spider web DNA: A new spin on noninvasive genetics of predator and prey. Plos One 10, e0142503 (2015).

31 Blake, M., McKeown, N. J., Bushell, M. L. T. \& Shaw, P. W. DNA extraction from spider webs. Conserv Genet Resour 8, 219-221 (2016). 
32 Corse, E. et al. One-locus-several-primers: A strategy to improve the taxonomic and haplotypic coverage in diet metabarcoding studies. Ecol Evol 9, 4603-4620 (2019).

33 Foelix, R. F. Biology of spiders. 3 edn, (Oxford University Press, 2011).

34 Blackledge, T. A., Kuntner, M. \& Agnarsson, I. in Advances in Insect Physiology, Vol 41: Spider physiology and behaviour - Behaviour Vol. 41 Advances in Insect Physiology (ed J. Casas) 175262 (Elsevier, 2011).

35 Sahni, V., Blackledge, T. A. \& Dhinojwala, A. Viscoelastic solids explain spider web stickiness. Nat Commun 1 (2010).

36 Leray, M. et al. A new versatile primer set targeting a short fragment of the mitochondrial COI region for metabarcoding metazoan diversity: application for characterizing coral reef fish gut contents. Front Zool 10, 34-34 (2013).

37 Toju, H., Tanabe, A. S., Yamamoto, S. \& Sato, H. High-coverage ITS primers for the DNA-based identification of Ascomycetes and Basidiomycetes in environmental samples. PLOS ONE 7, e40863 (2012).

38 Klindworth, A. et al. Evaluation of general 165 ribosomal RNA gene PCR primers for classical and next-generation sequencing-based diversity studies. Nucleic Acids Res 41, e1 (2013).

39 Bolyen, E. et al. Reproducible, interactive, scalable and extensible microbiome data science using QIIME 2. Nature Biotechnol 37, 852-857 (2019).

40 Quast, C. et al. The SILVA ribosomal RNA gene database project: improved data processing and web-based tools. Nucleic Acids Res 41, D590-D596 (2012).

41 Abarenkov, K. et al. The UNITE database for molecular identification of fungi \&\#x2013; recent updates and future perspectives. New Phytol 186, 281-285 (2010).

42 Ratnasingham, S. \& Hebert, P. D. N. bold: The Barcode of Life Data System (http://www.barcodinglife.org). Mol Ecol Notes 7, 355-364 (2007).

43 Rognes, T., Flouri, T., Nichols, B., Quince, C. \& Mahé, F. VSEARCH: a versatile open source tool for metagenomics. PeerJ 4, e2584 (2016). 
44 Lozupone, C. A., Hamady, M., Kelley, S. T. \& Knight, R. Quantitative and qualitative beta diversity measures lead to different insights into factors that structure microbial communities. Appl Environ Microb 73, 1576-1585 (2007).

45 Townzen, J. S., Brower, A. V. Z. \& Judd, D. D. Identification of mosquito bloodmeals using mitochondrial cytochrome oxidase subunit I and cytochrome b gene sequences. Med Vet Entomol 22, 386-393 (2008).

46 Gariepy, T. D., Lindsay, R., Ogden, N. \& Gregory, T. R. Identifying the last supper: utility of the DNA barcode library for bloodmeal identification in ticks. Mol Ecol Res 12, 646-652 (2012).

47 Schnell, I. B. et al. Screening mammal biodiversity using DNA from leeches. Curr Biol 22, R262-R263 (2012).

48 Calvignac-Spencer, S. et al. Carrion fly-derived DNA as a tool for comprehensive and costeffective assessment of mammalian biodiversity. Mol Ecol 22, 915-924 (2013).

49 Kennedy, S. R. et al. High-throughput sequencing for community analysis: the promise of DNA barcoding to uncover diversity, relatedness, abundances and interactions in spider communities. Dev Genes Evol 230, 185-201 (2020).

50 Watanabe, T. Web tuning of an orb-web spider, Octonoba sybotides, regulates prey-catching behaviour. Proc Roy Soc B 267, 565-569 (2000).

51 Riechert, S. E. \& Luczak, J. in Spider communication: mechanisms and ecological significance (eds Peter N. Witt \& Jerome S. Rovner) 353-385 (Princeton University Press, 1982).

52 Uetz, G. W. \& Hartsock, S. P. Prey Selection in an orb-weaving spider: Micrathena gracilis (Araneae: Araneidae). Psyche 94, 103-116 (1987).

53 Blackledge, T. A. Prey capture in orb weaving spiders: are we using the best metric? J Arachnol 39, 205-210 (2011).

54 Young, J. M., Weyrich, L. S. \& Cooper, A. Forensic soil DNA analysis using high-throughput sequencing: A comparison of four molecular markers. Forensic Sci Int-Gen 13, 176-184 (2014). 
55 Šantl-Temkiv, T., Gosewinkel, U., Starnawski, P., Lever, M. \& Finster, K. Aeolian dispersal of bacteria in southwest Greenland: their sources, abundance, diversity and physiological states. FEMS Microbiol Ecol 94 (2018).

56 Vestergaard, D. V. et al. Pig farmers' homes harbor more diverse airborne bacterial communities than pig stables or suburban homes. Front Microbio/ 9, 870 (2018).

57 Lister, B. C. \& Garcia, A. Climate-driven declines in arthropod abundance restructure a rainforest food web. PNAS 115, E10397-E10406 (2018).

58 Hallmann, C. A. et al. More than 75 percent decline over 27 years in total flying insect biomass in protected areas. Plos One 12, e0185809 (2017).

59 Sánchez-Bayo, F. \& Wyckhuys, K. A. G. Worldwide decline of the entomofauna: A review of its drivers. Biol Conserv 232, 8-27 (2019).

60 European Commission. EU Pollinators Initiative: The EU approach to tackle pollinator decline. (2018).

61 Schneider, J. et al. Detection of invasive mosquito vectors using environmental DNA (eDNA) from water samples. Plos One 11, e0162493 (2016).

62 Hartford, H., Baker, E. W., Kono, T., Delfinado, M. \& Keifer, W. E. Illustrated guide to plant abnormalities caused by eriophyid mites in North America. (1982).

63 Skoracka, A. Quackgrass- and ryegrass-adapted populations of the cereal rust mite, Abacarus hystrix (Acari: Eriophyidae), differ in their potential for wheat, Triticum aestivum, colonization. Bull Entomol Res 99, 33-39 (2009).

64 Gagné, R. J. A catalog of the Cecidomyiidae (Diptera) of the world. (Entomological Society of Washington, 2004). mushroom pests Lycoriella auripila (Diptera: Sciaridae) and Megaselia halterata (Diptera: Phoridae) by Steinernema feltiae (Nematoda: Steinernematidae) in field experiments. Ann Appl Biol 131, 359-368 (1997). 
66 Day, R. K. et al. in Biological control in IPM systems in Africa (ed P. Neuenschwander, Borgemeister, C., Langewald, J.) 101-112 (2003).

67 McGaving, G. C. Bugs of the world. (Facts on File, 1993).

68 van Emden, H. F. \& Harrington, R. Aphids as crop pests. Vol. 2 (CABI, 2017).

69 Nelson, P. E., Dignani, M. C. \& Anaissie, E. J. Taxonomy, biology, and clinical aspects of Fusarium species. Clin Microbiol Rev 7, 479-504 (1994).

70 Andrade, O. A., Mathre, D. E. \& Sands, D. C. Natural suppression of take-all disease of wheat in Montana soils. Plant Soil 164, 9-18 (1994).

71 Kämper, J. et al. Insights from the genome of the biotrophic fungal plant pathogen Ustilago maydis. Nature 444, 97-101 (2006).

72 Barbara, D. J. \& Clewes, E. Plant pathogenic Verticillium species: how many of them are there? Mol Plant Pathol 4, 297-305 (2003).

73 Talbot, N. J. On the trail of a cereal killer: Exploring the biology of Magnaporthe grisea. Ann Rev Microbiol 57, 177-202 (2003).

74 Mansfield, J. et al. Top 10 plant pathogenic bacteria in molecular plant pathology. Mol Plant Pathol 13, 614-629 (2012).

75 Valentin, R. E., Fonseca, D. M., Nielsen, A. L., Leskey, T. C. \& Lockwood, J. L. Early detection of invasive exotic insect infestations using eDNA from crop surfaces. Front Ecol Envir 16, 265270 (2018).

76 Guarnaccia, V. et al. First report of Phyllosticta citricarpa and description of two new species, P. paracapitalensis and P. paracitricarpa, from citrus in Europe. Studies Mycol 87, 161-185 (2017).

77 Nicolaisen, M. et al. Fungal communities including plant pathogens in near surface air are similar across Northwestern Europe. Front Microbiol 8 (2017). 
78 Andersen, B. et al. Molecular and phenotypic descriptions of Stachybotrys chlorohalonata sp. nov. and two chemotypes of Stachybotrys chartarum found in water-damaged buildings.

Mycologia 95, 1227-1238 (2003).

79 San-Blas, G. \& Calderone, R. A. Pathogenic fungi: Insights in molecular biology. 264 (Caister Academic Press, 2008).

80 Williamson, B., Tudzynski, B., Tudzynski, P. \& Van Kan, J. A. L. Botrytis cinerea: the cause of grey mould disease. Mol Plant Pathol 8, 561-580 (2007).

81 Hoffmann, K., Discher, S. \& Voigt, K. Revision of the genus Absidia (Mucorales, Zygomycetes) based on physiological, phylogenetic, and morphological characters; thermotolerant Absidia spp. form a coherent group, Mycocladiaceae fam. nov. Mycol Res 111, 1169-1183 (2007).

82 Wales, A. D. et al. Review of the carriage of zoonotic bacteria by arthropods, with special reference to Salmonella in mites, flies and litter beetles. Zoonoses Public HIth 57, 299-314 (2010).

83 Ciancio, A. Invertebrate bacteriology: function, evolution and biological ties (sustainability in plant and crop protection). 349 (Springer, 2016).

84 Tortora, G. J., Funke, B. R. \& Case, C. L. Microbiology: an introduction. 13 edn, 960 (Pearson, 2020). 


\section{Supplementary material 1: Additional literature overview}

\section{Spider webs as eDNA tool for biodiversity assessment of life's domains}

Matjaž Gregorič ${ }^{1 *}$, Denis Kutnjak², Katarina Bačnik ${ }^{2,3}$, Cene Gostinčar ${ }^{4,5}$, Anja Pecman², Maja Ravnikar², Matjaž Kuntner ${ }^{1,6}$

${ }^{1}$ Jovan Hadži Institute of Biology, Scientific Research Centre of the Slovenian Academy of Sciences and Arts, Novi trg 2, 1000 Ljubljana, Slovenia

${ }^{2}$ Department of Biotechnology and Systems Biology, National Institute of Biology, Večna pot 111, 1000 Ljubljana, Slovenia

${ }^{3}$ Jožef Stefan International Postgraduate School, Jamova cesta 39, 1000 Ljubljana, Slovenia

${ }^{4}$ Department of Biology, Biotechnical Faculty, University of Ljubljana, Jamnikarjeva ulica 101, 1000 Ljubljana, Slovenia

${ }^{5}$ Lars Bolund Institute of Regenerative Medicine, BGI-Qingdao, Qingdao 266555, China

${ }^{6}$ Department of Organisms and Ecosystems Research, National Institute of Biology, Večna pot 111, 1000 Ljubljana, Slovenia

*Corresponding author: Matjaž Gregorič, matjaz.gregoric@zrc-sazu.si, matjaz.gregoric@gmail.com. 


\section{Additional literature overview}

Recently, spider webs have been proposed as a novel source of eDNA. Xu et al. ${ }^{1}$ maintained two black widow species (Latrodectus hesperus and L. mactans) in controlled laboratory conditions, feeding them a single prey type, the house cricket Acheta domestica. Using conventional PCR, they detected genetic traces of host and prey, and both spider and prey DNA remained detectable for months ${ }^{1}$. Blake et al. ${ }^{2}$ confirmed these findings by amplifying spider DNA from silk of the laboratory kept bird spider Psalmopoeus, and from the daddy long leg spider Pholcus phalangioides, sampled in a house. Additionally, in a study investigating ways of improving the taxonomic coverage in DNA metabarcoding, Corse et al. ${ }^{3}$ included spider webs as one of several sources of eDNA. Because spider webs are ubiquitous and can be easily collected, the potential use of web derived eDNA goes well beyond identifying spiders and their prey. For example, spider webs are known to accumulate plant pollen and agrochemical spray ${ }^{4,5}$. Thus, utilizing the genetic material obtained from spider webs represents an alternative, novel, and potentially powerful sampling method to supplement and complement traditional methods.

While these studies are valuable for introducing the concept of eDNA from spider webs, they urgently call for a focused investigation of the utility of spider webs as an eDNA source. Specifically, the two studies ${ }^{1,2}$ targeting host and prey DNA in a single-species approach, suffer from two major shortcomings. First, sampling webs in controlled conditions means that factors like UV light, heat, humidity, wind, and rain have likely been reduced compared to field conditions. Second, these two studies failed to apply standard laboratory controls, e.g. controlling for possible isolation inhibition, false positive/negative results, and optimal assay performance throughout a wide concentration of isolated target $\mathrm{DNA}^{6-8}$. Furthermore, Corse et al. ${ }^{3}$ show that spider webs accumulate a diversity of arthropod genetic traces, but their study focused on identification resolution of different metabarcoding approaches for eDNA from different environments, rather than spider webs as an eDNA source, per se. Here, we first tested the detection of a model arthropod target in the field. Second, using a metabarcoding approach, we investigated the utility of spider web eDNA in general biodiversity monitoring.

\section{References} genetics of predator and prey. Plos One 10, e0142503 (2015).

2 Blake, M., McKeown, N. J., Bushell, M. L. T. \& Shaw, P. W. DNA extraction from spider webs. Conservation Genetics Resources 8, 219-221 (2016).

3 Corse, E. et al. One-locus-several-primers: A strategy to improve the taxonomic and haplotypic coverage in diet metabarcoding studies. Ecology and Evolution 9, 4603-4620 (2019).

4 Samu, F., Matthews, G. A., Lake, D. \& Vollrath, F. Spider webs are efficient collectors of agrochemical spray. Pesticide Science 36, 47-51 (1992).

5 Eggs, B. \& Sanders, D. Herbivory in spiders: The importance of pollen for orb-weavers. Plos One 8, e82637 (2013).

$6 \quad$ Kogovšek, P. et al. in Metagenomics: Managing, Analysing and Visualising Data. (Trust Genome Campus).

7 Kutnjak, D. et al. Deep sequencing of virus-derived small interfering RNAs and RNA from viral particles shows highly similar mutational landscapes of a plant virus population. Journal of virology 89, 4760-4769 (2015).

8 Kutnjak, D. et al. Complete genome sequences of new divergent potato virus $X$ isolates and discrimination between strains in a mixed infection using small RNAs sequencing approach. Virus research 191, 45-50 (2014). 


\section{Supplementary material 2: Additional methods}

\section{Spider webs as eDNA tool for biodiversity assessment of life's domains}

Matjaž Gregorič ${ }^{1 *}$, Denis Kutnjak², Katarina Bačnik ${ }^{2,3}$, Cene Gostinčar ${ }^{4,5}$, Anja Pecman ${ }^{2}$, Maja Ravnikar², Matjaž Kuntner ${ }^{1,6}$

${ }^{1}$ Jovan Hadži Institute of Biology, Scientific Research Centre of the Slovenian Academy of Sciences and Arts, Novi trg 2, 1000 Ljubljana, Slovenia

2Department of Biotechnology and Systems Biology, National Institute of Biology, Večna pot 111, 1000 Ljubljana, Slovenia

${ }^{3}$ Jožef Stefan International Postgraduate School, Jamova cesta 39, 1000 Ljubljana, Slovenia

${ }^{4}$ Department of Biology, Biotechnical Faculty, University of Ljubljana, Jamnikarjeva ulica 101, 1000 Ljubljana, Slovenia

${ }^{5}$ Lars Bolund Institute of Regenerative Medicine, BGI-Qingdao, Qingdao 266555, China

${ }^{6}$ Department of Organisms and Ecosystems Research, National Institute of Biology, Večna pot 111, 1000 Ljubljana, Slovenia

*Corresponding author: Matjaž Gregorič, matjaz.gregoric@zrc-sazu.si, matjaz.gregoric@gmail.com. 


\section{Protocol for DNA isolation}

This protocol is an adapted protocol of the PowerLyzer ${ }^{\circledR}$ PowerSoil ${ }^{\circledR}$ DNA Isolation Kit (Qiagen, USA).

1. Add sample into provided PowerBead tube.

2. Add $750 \mu$ l of bead solution.

3. Vortex briefly, and briefly spin-down centrifuge.

4. Add $60 \mu \mathrm{l}$ of $\mathrm{C} 1$ solution. If $\mathrm{C} 1$ solution precipitated, heat to $60^{\circ} \mathrm{C}$ until dissolved.

5. Vortex briefly or invert tube several times.

6. Homogenize using FastPrep (XX): $45 \mathrm{~s}$, MP adapter (24x), $6.5 \mathrm{~ms}$.

7. Incubate at $70^{\circ} \mathrm{C}$ for $10 \mathrm{~min}$ while shaking at $2000 \mathrm{rpm}$.

8. Homogenize using FastPrep (XX): $45 \mathrm{~s}, \mathrm{MP}$ adapter (24x), $6.5 \mathrm{~ms}$.

9. Centrifuge at $10,000 \times \mathrm{g}, 2 \times$ for $1 \mathrm{~min}$ at room temperature, in between tap with fingers to remove foam.

10. Transfer 400-500 $\mu \mathrm{l}$ of supernatant into new $2 \mathrm{ml}$ collection tube. Avoid transferring parts of pellet. If there is not enough supernatant, repeat centrifuge at $10,000 \mathrm{xg}$ for $1 \mathrm{~min}$ at room temperature.

11. Add $250 \mu$ of $\mathrm{C} 2$ solution to supernatant.

12. Vortex briefly.

13. Incubate at $4^{\circ} \mathrm{C}$ for $5 \mathrm{~min}$.

14. Centrifuge at $10,000 \times \mathrm{g}$ for $1 \mathrm{~min}$ at room temperature.

15. Transfer $600 \mu \mathrm{L}$ of supernatant into new $2 \mathrm{ml}$ collection tube. Avoid transferring parts of pellet.

16. Add $200 \mu \mathrm{l}$ of solution C3.

17. Vortex briefly.

18. Incubate at $4^{\circ} \mathrm{C}$ for $5 \mathrm{~min}$.

19. Centrifuge at $10,000 \times \mathrm{g}$ for $1 \mathrm{~min}$ at room temperature.

20. Transfer $625 \mu \mathrm{l}$ of supernatant into new $2 \mathrm{ml}$ collection tube. Avoid transferring parts of pellet.

21. Add $1000 \mu$ l of solution C4 to the supernatant.

22. Vortex for $5 \mathrm{~s}$, spin-down centrifuge briefly.

23. Transfer $600 \mu$ l of supernatant to a spin filter.

24. Centrifuge at $10,000 \times \mathrm{g}$ for $1 \mathrm{~min}$ at room temperature.

25. Discard the flow-through and place spin filter into clean $2 \mathrm{ml}$ collection tube.

26. Add an additional $600 \mu \mathrm{l}$ to spin filter.

27. Centrifuge at $10,000 \times \mathrm{g}$ for $1 \mathrm{~min}$ at room temperature.

28. Discard the flow-through and place spin filter into clean $2 \mathrm{ml}$ collection tube.

29. Add the remaining supernatant on spin filter.

30. Centrifuge at $10,000 \times \mathrm{g}$ for $1 \mathrm{~min}$ at room temperature.

31. Discard the flow-through and place spin filter into clean $2 \mathrm{ml}$ collection tube.

32. Add $500 \mu \mathrm{l}$ of solution C5.

33. Centrifuge at $10,000 \times \mathrm{g}$ for $30 \mathrm{~s}$ at room temperature.

34. Discard the flow-through and place spin filter into clean $2 \mathrm{ml}$ collection tube.

35. Centrifuge at $10,000 \times \mathrm{g}$ for $1 \mathrm{~min}$ at room temperature.

36. Discard the flow-through and place spin filter into clean $2 \mathrm{ml}$ collection tube.

37. Add $75 \mu \mathrm{l}$ of solution $\mathrm{C} 6$ to the center of the filter membrane, without touching membrane.

38. Incubate at room temperature for 3-5 $\mathrm{min}$.

39. Centrifuge at $10,000 \times \mathrm{g}$ for $30 \mathrm{~s}$ at room temperature.

40. Discard the spin filter, keep DNA frozen. 


\section{Single-species eDNA detection}

Table S1: Adom1 and Adom2 primer details.

\begin{tabular}{|c|c|c|c|c|}
\hline Name & Sequence $\left(5^{\prime}->3^{\prime}\right)$ & 5 ' modification & 3' modification & Cleaning \\
\hline $\begin{array}{l}\text { Adom1_F } \\
\text { (forward) }\end{array}$ & TCCACCTTTATCAACAGGAATCG & & & STD \\
\hline $\begin{array}{l}\text { Adom1_R } \\
\text { (reverse) }\end{array}$ & TTAACGGCTCCCAGAATTGATG & & & STD \\
\hline $\begin{array}{l}\text { Adom1_P } \\
\text { (probe) }\end{array}$ & CCACGCCGGAGCATCTGTTGATTT & /56-FAM/ & $\begin{array}{l}\text { 3' Zen lowa } \\
\text { BlackTM FQ }\end{array}$ & HPLC \\
\hline $\begin{array}{l}\text { Adom2_F } \\
\text { (forward) }\end{array}$ & CATCAATTCTGGGAGCCGTTA & & & STD \\
\hline $\begin{array}{l}\text { Adom2_R } \\
\text { (reverse) }\end{array}$ & GATAATAATAGGAGGAGGGCAGTGATT & & & STD \\
\hline Adom2_P & CCTGGGATGTCATTAGA & FAM & MGB NFQ & HPLC \\
\hline
\end{tabular}

Table S2: Reaction mixes for qPCRs using Adom1 primers. We added $2 \mu$ of isolated DNA sample for a $10 \mu \mathrm{l}$ total qPCR.

\begin{tabular}{ll} 
Adom1 mastermix & Volume per reaction $(\mu \mathrm{l})$ \\
\hline Water & 0.2 \\
2× TaqMan Universal master mix (ABI) & 5 \\
Adom1_F $(10 \mu \mathrm{M})$ & 0.9 \\
Adom1_R $(10 \mu \mathrm{M})$ & 0.9 \\
Adom1_P $(2.5 \mu \mathrm{M})$ & 1 \\
\hline Sum & 8.0
\end{tabular}

Table S3: Reaction mixes for qPCRs using Adom2 primers. We added $2 \mu$ l of isolated DNA sample for a $10 \mu l$ total qPCR.

\begin{tabular}{ll} 
Adom2 mastermix & Volume per reaction $(\mu \mathrm{l})$ \\
\hline Water & 0.2 \\
2× TaqMan Universal master mix (ABI) & 5 \\
Adom2_F $(10 \mu \mathrm{M})$ & 0.9 \\
Adom2_R $(10 \mu \mathrm{M})$ & 0.9 \\
Adom2_MGB_P $(2.5 \mu \mathrm{M})$ & 1 \\
\hline Sum & 8.0
\end{tabular}

Table S4: Reaction mixes for qPCRs using the "Eukaryotic 18S rRNA Endogenous Control" (Applied Biosystems, USA). We added $2 \mu$ of isolated DNA sample for a $10 \mu$ l total qPCR.

\begin{tabular}{ll} 
Adom2 mastermix & Volume per reaction $(\mu \mathrm{l})$ \\
\hline Water & 2.5 \\
$2 \times$ TaqMan Universal master mix (ABI) & 5 \\
Primers/probes $(20 \mathrm{x})$ & 0.5 \\
\hline Sum & 8.0
\end{tabular}


bioRxiv preprint doi: https://doi.org/10.1101/2020.07.18.209999; this version posted July 19, 2020. The copyright holder for this preprint (which was not certified by peer review) is the author/funder, who has granted bioRxiv a license to display the preprint in perpetuity. It is made available under aCC-BY-NC-ND 4.0 International license.

Table S5: qPCR amplification protocol for Adom1 amplification, using the 7900HT Fast Real-Time PCR System (Applied Biosystems, USA).

\begin{tabular}{l} 
PCR cycling conditions \\
\hline $50^{\circ} \mathrm{C}$ FOR 2 min \\
\hline $95^{\circ} \mathrm{C}$ for $10 \mathrm{~min}$ \\
\hline 45 cycles at: \\
$-\quad 95^{\circ} \mathrm{C}$ for $15 \mathrm{~s}$ \\
$-\quad 60^{\circ} \mathrm{C}$ for $60 \mathrm{~s}$ \\
\hline
\end{tabular}




\section{DNA metabarcoding}

Table S6: Sampling details for the metabarcoding experiment. The sample codes (A, B, C) for each sample correspond to Qiime2 visual output files (Supplementary material 3).

\begin{tabular}{|c|c|c|c|c|c|c|c|}
\hline Animals & Fungi & Bacteria & Web type & Forest type & Locality & Coordinates & Sampling date \\
\hline A01 & B01 & $\mathrm{CO1}$ & Sheet web & Submediterranean & Locality 1 & $\begin{array}{l}45.575873 \\
13.856277\end{array}$ & $5 . x .2018$ \\
\hline A02 & B02 & $\mathrm{CO} 2$ & Sheet web & Submediterranean & Locality 1 & $\begin{array}{l}\text { 45.575873 } \\
13.856277\end{array}$ & 5.x.2018 \\
\hline A03 & B03 & $\mathrm{CO3}$ & Sheet web & Submediterranean & Locality 1 & $\begin{array}{l}45.575873 \\
13.856277\end{array}$ & 5.x.2018 \\
\hline A04 & B04 & $\mathrm{CO4}$ & Sheet web & Submediterranean & Locality 1 & $\begin{array}{l}45.575873 \\
13.856277\end{array}$ & 5.x.2018 \\
\hline A05 & B05 & $\mathrm{CO5}$ & Sheet web & Submediterranean & Locality 1 & $\begin{array}{l}45.575873 \\
13.856277\end{array}$ & 5.x.2018 \\
\hline A06 & B06 & $\mathrm{CO6}$ & Sheet web & Continental & Locality 2 & $\begin{array}{l}46.515795 \\
15.690766\end{array}$ & 28.ix.2018 \\
\hline A07 & B07 & $\mathrm{CO}$ & Sheet web & Continental & Locality 2 & $\begin{array}{l}46.515795 \\
15.690766\end{array}$ & 28.ix.2018 \\
\hline A08 & B08 & $\mathrm{CO8}$ & Sheet web & Continental & Locality 2 & $\begin{array}{l}46.515795 \\
15.690766\end{array}$ & 28.ix.2018 \\
\hline A09 & B09 & Co9 & Sheet web & Continental & Locality 2 & $\begin{array}{l}46.515795 \\
15.690766\end{array}$ & 28.ix.2018 \\
\hline A10 & B10 & C10 & Sheet web & Continental & Locality 2 & $\begin{array}{l}46.515795 \\
15.690766\end{array}$ & 28.ix.2018 \\
\hline A11 & B11 & $\mathrm{C} 11$ & Orb web & Continental & Locality 2 & $\begin{array}{l}46.515795 \\
15.690766\end{array}$ & 28.ix.2018 \\
\hline A12 & B12 & $\mathrm{C} 12$ & Orb web & Continental & Locality 2 & $\begin{array}{l}46.515795 \\
15.690766\end{array}$ & 28.ix.2018 \\
\hline A13 & B13 & $\mathrm{C} 13$ & Orb web & Continental & Locality 2 & $\begin{array}{l}46.515795 \\
15.690766\end{array}$ & 28.ix.2018 \\
\hline A14 & B14 & C14 & Orb web & Continental & Locality 2 & $\begin{array}{l}46.515795 \\
15.690766\end{array}$ & 28.ix.2018 \\
\hline A15 & B15 & C15 & Orb web & Continental & Locality 2 & $\begin{array}{l}46.515795 \\
15.690766\end{array}$ & 28.ix.2018 \\
\hline A16 & B16 & C16 & Sheet web & Submediterranean & Locality 1 & $\begin{array}{l}45.575873 \\
13.856277\end{array}$ & 26.ix.2017 \\
\hline A17 & B17 & $\mathrm{C} 17$ & Sheet web & Submediterranean & Locality 1 & $\begin{array}{l}45.575873 \\
13.856277\end{array}$ & 26.ix.2017 \\
\hline A18 & B18 & C18 & Sheet web & Submediterranean & Locality 1 & $\begin{array}{l}45.575873 \\
13.856277\end{array}$ & 26.ix.2017 \\
\hline A19 & B19 & C19 & Sheet web & Submediterranean & Locality 1 & $\begin{array}{l}45.575873 \\
13.856277\end{array}$ & 26.ix.2017 \\
\hline A20 & $\mathrm{B} 20$ & $\mathrm{C} 20$ & Sheet web & Submediterranean & Locality 1 & $\begin{array}{l}45.575873 \\
13.856277\end{array}$ & 26.ix.2017 \\
\hline A21 & B21 & $\mathrm{C} 21$ & Orb web & Submediterranean & Locality 1 & $\begin{array}{l}45.575873 \\
13.856277\end{array}$ & 26.ix.2017 \\
\hline A22 & B22 & $\mathrm{C} 22$ & Orb web & Submediterranean & Locality 1 & $\begin{array}{l}45.575873 \\
13.856277\end{array}$ & 26.ix.2017 \\
\hline A23 & B23 & $\mathrm{C} 23$ & Orb web & Submediterranean & Locality 1 & $\begin{array}{l}45.575873 \\
13.856277\end{array}$ & 26.ix.2017 \\
\hline A24 & B24 & $\mathrm{C} 24$ & Orb web & Submediterranean & Locality 1 & $\begin{array}{l}45.575873 \\
13.856277\end{array}$ & 26.ix.2017 \\
\hline A25 & B25 & $\mathrm{C} 25$ & Orb web & Submediterranean & Locality 1 & $\begin{array}{l}45.575873 \\
13.856277\end{array}$ & 26.ix.2017 \\
\hline
\end{tabular}


bioRxiv preprint doi: https://doi.org/10.1101/2020.07.18.209999; this version posted July $19,2020$. The copyright holder for this preprin (which was not certified by peer review) is the author/funder, who has granted bioRxiv a license to display the preprint in perpetuity. It is made available under aCC-BY-NC-ND 4.0 International license.

Table S7: The number of obtained reads for all samples. Red lines mark the omitted samples, i.e. the chosen sample/amplicon combination for beta diversity estimation.

\begin{tabular}{|c|c|c|c|c|c|}
\hline Sample ID & Animal reads & Sample ID & Fungi reads & Sample ID & Bacteria reads \\
\hline A12 & 31797 & B01 & 94101 & $\mathrm{C06}$ & 140830 \\
\hline A11 & 23215 & B09 & 66780 & $\mathrm{CO9}$ & 128351 \\
\hline A13 & 22053 & B04 & 63497 & $\mathrm{C} 13$ & 128288 \\
\hline A24 & 20934 & MockComm & 56655 & $\mathrm{C} 23$ & 125484 \\
\hline A14 & 14717 & B18 & 56564 & $\mathrm{CO1}$ & 123588 \\
\hline A01 & 14345 & B19 & 53879 & MockComm & 123466 \\
\hline A23 & 7330 & B07 & 46441 & $\mathrm{C} 20$ & 122900 \\
\hline A05 & 7137 & B10 & 46312 & C14 & 121516 \\
\hline A21 & 5262 & B02 & 43853 & $\mathrm{CO3}$ & 119455 \\
\hline A17 & 4930 & B06 & 40036 & C10 & 117504 \\
\hline A15 & 3431 & B08 & 38681 & $\mathrm{CO}$ & 115460 \\
\hline A08 & 2745 & B25 & 35287 & $\mathrm{C} 18$ & 111457 \\
\hline A22 & 2710 & B03 & 32613 & $\mathrm{C} 17$ & 107573 \\
\hline A18 & 2162 & B05 & 15780 & $\mathrm{CO} 4$ & 106685 \\
\hline A25 & 1704 & B13 & 14283 & $\mathrm{C} 25$ & 99389 \\
\hline A16 & 1654 & B17 & 13272 & $\mathrm{CO5}$ & 96528 \\
\hline A02 & 1648 & B21 & 13196 & $\mathrm{CO8}$ & 96393 \\
\hline A04 & 1281 & B15 & 11228 & $\mathrm{CO} 2$ & 95965 \\
\hline A10 & 1021 & B20 & 11182 & $\mathrm{C} 21$ & 81834 \\
\hline A19 & 978 & B16 & 8410 & $\mathrm{C} 24$ & 35137 \\
\hline A06 & 971 & B12 & 7862 & C19 & 32071 \\
\hline A03 & 790 & B23 & 3160 & $\mathrm{C} 12$ & 25121 \\
\hline A07 & 584 & B24 & 1976 & $\mathrm{C} 22$ & 16941 \\
\hline A20 & 491 & B14 & 1840 & C15 & 15906 \\
\hline A09 & 116 & B11 & 1361 & Neg-4 & 66 \\
\hline MockComm & 0 & B22 & 0 & Neg-1 & 8 \\
\hline Neg-1 & 0 & Neg-1 & 0 & Neg-3 & 6 \\
\hline Neg-2 & 0 & Neg-2 & 0 & C11 & 3 \\
\hline Neg-3 & 0 & Neg-3 & 0 & C16 & 1 \\
\hline Neg-4 & 0 & Neg-4 & 0 & Neg-2 & 1 \\
\hline
\end{tabular}

Table S8: Primers used in DNA metabarcoding.

\begin{tabular}{|c|c|c|c|}
\hline $\begin{array}{l}\text { Taxon, locus, size, } \\
\text { reference }\end{array}$ & Primer names & Sequence $\left(5^{\prime}\right.$-> $\left.3^{\prime}\right)$ & Illumina overhang \\
\hline $\begin{array}{l}\text { Metazoa, CO1, } \\
313 \text { bp, }{ }^{1}\end{array}$ & $\begin{array}{l}\text { mlCOlintF (fwd) } \\
\text { jgHCO2198 (rev) }\end{array}$ & $\begin{array}{l}\text { GGWACWGGWTGAACWGTWTA } \\
\text { YCCYCC } \\
\text { TAAACTTCAGGGTGACCAAARAA } \\
\text { YCA }\end{array}$ & $\begin{array}{l}\text { TCGTCGGCAGCGTCAGATGTGTATAAGA } \\
\text { GACAG } \\
\text { GTCTCGTGGGCTCGGAGATGTGTATAAG } \\
\text { AGACAG }\end{array}$ \\
\hline $\begin{array}{l}\text { Fungi, ITS, 300- } \\
400 \mathrm{bp},{ }^{2}\end{array}$ & $\begin{array}{l}\text { ITS3_KYO2 (fwd) } \\
\text { ITS4 (rev) }\end{array}$ & $\begin{array}{l}\text { GATGAAGAACGYAGYRAA } \\
\text { TCCTCCGCTTATTGATATGC }\end{array}$ & $\begin{array}{l}\text { TCGTCGGCAGCGTCAGATGTGTATAAGA } \\
\text { GACAG } \\
\text { GTCTCGTGGGCTCGGAGATGTGTATAAG } \\
\text { AGACAG }\end{array}$ \\
\hline $\begin{array}{l}\text { Bacteria, 16S V3- } \\
\text { V4, } 464 \mathrm{bp},{ }^{3}\end{array}$ & $\begin{array}{l}\text { S-D-Bact-0341-b-S-17 } \\
\text { (fwd) } \\
\text { S-D-Bact-0785-a-A-21 } \\
\text { (rev) }\end{array}$ & $\begin{array}{l}\text { CCTACGGGNGGCWGCAG } \\
\text { GACTACHVGGGTATCTAATCC }\end{array}$ & $\begin{array}{l}\text { TCGTCGGCAGCGTCAGATGTGTATAAGA } \\
\text { GACAG } \\
\text { GTCTCGTGGGCTCGGAGATGTGTATAAG } \\
\text { AGACAG }\end{array}$ \\
\hline
\end{tabular}


Table S9: PCR protocol for amplification of metabarcoding primers. To avoid amplification biases, we chose an amount of cycles where no reactions were saturated. We estimated PCR saturation using gel electrophoresis, i.e. we chose conditions where DNA bands on the gel were not or barely visible.

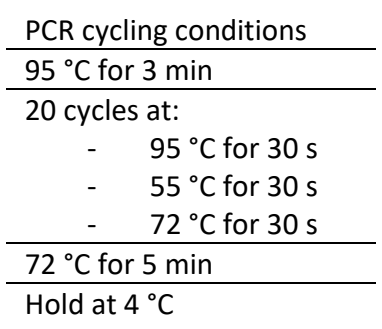

\section{References}

1 Leray, M. et al. A new versatile primer set targeting a short fragment of the mitochondrial $\mathrm{COI}$ region for metabarcoding metazoan diversity: application for characterizing coral reef fish gut contents. Frontiers in Zoology 10, 34-34 (2013).

2 Toju, H., Tanabe, A. S., Yamamoto, S. \& Sato, H. High-coverage ITS primers for the DNA-based identification of Ascomycetes and Basidiomycetes in environmental samples. PLOS ONE 7, e40863 (2012).

3 Klindworth, A. et al. Evaluation of general $16 \mathrm{~S}$ ribosomal RNA gene PCR primers for classical and next-generation sequencing-based diversity studies. Nucleic Acids Res 41, e1 (2013). 


\section{Supplementary material 3: Additional DNA metabarcoding results}

\section{Spider webs as eDNA tool for biodiversity assessment of life's domains}

Matjaž Gregorič ${ }^{1 *}$, Denis Kutnjak², Katarina Bačnik ${ }^{2,3}$, Cene Gostinčar ${ }^{4,5}$, Anja Pecman ${ }^{2}$, Maja Ravnikar², Matjaž Kuntner ${ }^{1,6}$

${ }^{1}$ Jovan Hadži Institute of Biology, Scientific Research Centre of the Slovenian Academy of Sciences and Arts, Novi trg 2, 1000 Ljubljana, Slovenia

2Department of Biotechnology and Systems Biology, National Institute of Biology, Večna pot 111, 1000 Ljubljana, Slovenia

${ }^{3}$ Jožef Stefan International Postgraduate School, Jamova cesta 39, 1000 Ljubljana, Slovenia

${ }^{4}$ Department of Biology, Biotechnical Faculty, University of Ljubljana, Jamnikarjeva ulica 101, 1000 Ljubljana, Slovenia

${ }^{5}$ Lars Bolund Institute of Regenerative Medicine, BGI-Qingdao, Qingdao 266555, China

${ }^{6}$ Department of Organisms and Ecosystems Research, National Institute of Biology, Večna pot 111, 1000 Ljubljana, Slovenia

*Corresponding author: Matjaž Gregorič, matjaz.gregoric@zrc-sazu.si, matjaz.gregoric@gmail.com. 


\section{Alpha diversity: additional results}

The statistical analysis of the Shannon index of alpha diversity showed that in the two forests, webs accumulate an equal diversity of bacterial $(p=0.208, H=1.587)$, fungal $(p=0.198, H=1.659)$ and animal $(p=0.325, H=0.968)$ eDNA. The sampling year yielded a similar diversity of eDNA (bacteria: $p$ $=0.413, \mathrm{H}=0.671$; fungi: $\mathrm{p}=0.200, \mathrm{H}=1.644$; animals: $\mathrm{p}=0.292, \mathrm{H}=1.111$ ). Compared to orb webs, sheet webs accumulated a higher diversity of bacterial $(p=0.051, H=3.813)$ and fungal $(p=0.025, H$ $=5.000)$ eDNA, but not animal eDNA ( $p=0.089, \mathrm{H}=2.883)$.

\section{Number of OTUs and lists of taxa.}
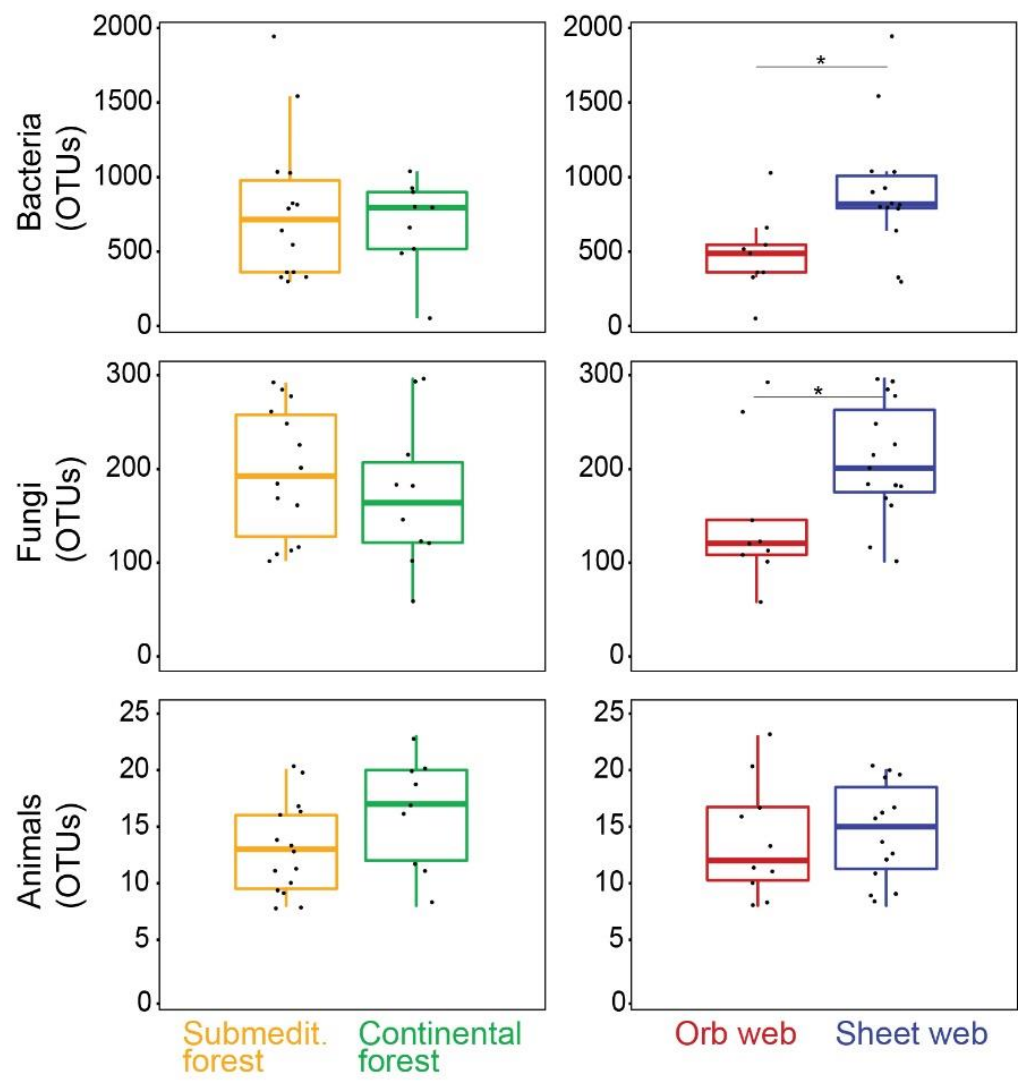

Figure 1: Average operational taxonomic unit (OTU) number per web. Data are shown for three different taxonomic groups (Bacteria, Fungi, Animals) and grouped by factors designated by color. The distribution of values for each factor is represented by box-whisker plots. In the two forests, webs on average accumulated an equal number of bacterial $(p=0.928, U=61)$, fungal $(p=0.596, U=$ $60.5)$ and animal $(p=0.128, U=41.5)$ OTUs. Compared to orb webs, sheet webs on average accumulated more bacterial $(p=0.018, U=25)$ and fungal $(p=0.039, U=32.5)$, but not animal $(p=$ $0.598, \mathrm{U}=60.5$ ) OTUs. Asterisks mark statistically significant differences. 
bioRxiv preprint doi: $\mathrm{https}$ ://doi. org/10.1101/2020.07 18.209999; this version posted July 19, 2020. The copyright holder for this preprint (which was not certified by peer review) is the author/funder, who has granted bioRxiv a license to display the preprint in perpetuity. It is made available under aCC-BY-NC-ND 4.0 International license.

Table 1: List of identified bacterial phyla with OTU counts, cumulative for all samples.

\begin{tabular}{lrrlr} 
Phylum & OTUs & & Phylum & OTUs \\
\cline { 5 - 5 } Acidobacteria & 424 & & Fusobacteria & 8 \\
Actinobacteria & 1184 & & Gemmatimonadetes & 148 \\
Armatimonadetes & 247 & & Hydrogenedentes & 1 \\
Bacteroidetes & 1699 & & Kiritimatiellaeota & 1 \\
BRC1 & 23 & & Lentisphaerae & 2 \\
Chlamydiae & 51 & & Nitrospirae & 4 \\
Chloroflexi & 297 & & Patescibacteria & 134 \\
Cyanobacteria & 156 & & Planctomycetes & 965 \\
Deferribacteres & 2 & & Proteobacteria & 2973 \\
Deinococcus-Thermus & 29 & & Rokubacteria & 1 \\
Dependentiae & 10 & & RsaHF231 \\
Elusimicrobia & 4 & & Tenericutes & 1 \\
Entotheonellaeota & 2 & & Verrucomicrobia & 9 \\
Epsilonbacteraeota & 2 & WPS-2 & 604 \\
FBP & 87 & N/a & 1710 \\
\cline { 3 - 4 } Firmicutes & 492 & Total & 11285
\end{tabular}

Table 2: A list of identified fungal phyla, cumulative for all samples, with OTU counts, and lists of all identified classes of Ascomycota and Basidiomycota, with OTU counts, respectively.

\begin{tabular}{lr}
\multicolumn{2}{c}{ Fungi } \\
\hline Phylum & OTUs \\
\hline Ascomycota & 2392 \\
Basidiomycota & 1440 \\
Blastocladiomycota & 1 \\
Chytridiomycota & 15 \\
Entomophthoromycota & 2 \\
Mortierellomycota & 7 \\
Mucoromycota & 10 \\
Rozellomycota & 1 \\
Zoopagomycota & 1 \\
N/a & 136 \\
\hline Total & 4005
\end{tabular}

\begin{tabular}{lr}
\multicolumn{2}{c}{ Ascomycota } \\
\hline Class & OTUs \\
\hline Arthoniomycetes & 12 \\
Dothideomycetes & 962 \\
Eurotiomycetes & 258 \\
Lecanoromycetes & 107 \\
Leotiomycetes & 280 \\
Orbiliomycetes & 74 \\
Pezizomycetes & 23 \\
Saccharomycetes & 33 \\
Sordariomycetes & 412 \\
Taphrinomycetes & 12 \\
N/a & 219 \\
\hline Total & 2392
\end{tabular}

\begin{tabular}{lr}
\multicolumn{2}{c}{ Basidiomycota } \\
\hline Class & OTUs \\
\hline Agaricomycetes & 960 \\
Agaricostilbomycetes & 13 \\
Atractiellomycetes & 3 \\
Cystobasidiomycetes & 51 \\
Dacrymycetes & 3 \\
Exobasidiomycetes & 50 \\
Malasseziomycetes & 2 \\
Microbotryomycetes & 44 \\
Pucciniomycetes & 31 \\
Spiculogloeomycetes & 5 \\
Tremellomycetes & 193 \\
Ustilaginomycetes & 14 \\
Wallemiomycetes & 8 \\
N/a & 63 \\
\hline Total & 1440
\end{tabular}


Table 3: Number of classes, orders, and families within each fungal phylum, cumulative for all samples.

\begin{tabular}{llll} 
Phylum & Classes & Orders & Families \\
\hline Ascomycota & 10 & 57 & 167 \\
Basidiomycota & 13 & 43 & 130 \\
Blastocladiomycota & 1 & 1 & 1 \\
Chytridiomycota & 1 & 1 & 1 \\
Entomophthoromycota & 1 & 1 & 1 \\
Mortierellomycota & 1 & 1 & 1 \\
Mucoromycota & 2 & 2 & 4 \\
Rozellomycota & 1 & 1 & 1 \\
Zoopagomycota & 1 & 1 & 1 \\
\hline Total & 31 & 108 & 307
\end{tabular}

Table 4: Lists of identified animal phyla, arthropod classes, and insect orders, with OTU counts, respectively. Cumulative for all samples.

\begin{tabular}{|c|c|c|c|c|c|}
\hline \multicolumn{2}{|c|}{ Animalia } & \multicolumn{2}{|c|}{ Arthropoda } & \multicolumn{2}{|c|}{ Insecta } \\
\hline Phylum & OTUs & Class & OTUs & Order & OTUs \\
\hline Arthropoda & 263 & Arachnida & 37 & Coleoptera & 3 \\
\hline Nematoda & 3 & Entognatha & 3 & Dermaptera & 1 \\
\hline Rotifera & 48 & Insecta & 218 & Diptera & 116 \\
\hline \multirow[t]{6}{*}{ Total } & 314 & $\mathrm{~N} / \mathrm{a}$ & 5 & Hemiptera & 28 \\
\hline & & Total & 263 & Hymenoptera & 59 \\
\hline & & & & Lepidoptera & 3 \\
\hline & & & & Thysanoptera & 2 \\
\hline & & & & $\mathrm{N} / \mathrm{a}$ & 6 \\
\hline & & & & Total & 218 \\
\hline
\end{tabular}

Table 5: Number of classes, orders and families in animal phyla, and number of families and genera in insect orders. Cumulative for all samples.

\begin{tabular}{llll} 
Phylum & Class & Order & Family \\
\hline Arthropoda & 3 & 13 & 47 \\
Nematoda & 1 & 1 & 1 \\
Rotifera & 1 & 2 & 2 \\
\hline Total & 5 & 16 & 50
\end{tabular}

\begin{tabular}{lll} 
Insecta & Families & Genera \\
\hline Coleoptera & 3 & 3 \\
Dermaptera & 1 & 1 \\
Diptera & 11 & 3 \\
Hemiptera & 7 & 11 \\
Hymenoptera & 9 & 18 \\
Lepidoptera & 1 & 1 \\
Thysanoptera & 1 & 1 \\
\hline Total & 33 & 38
\end{tabular}




\section{Beta diversity: additional results}

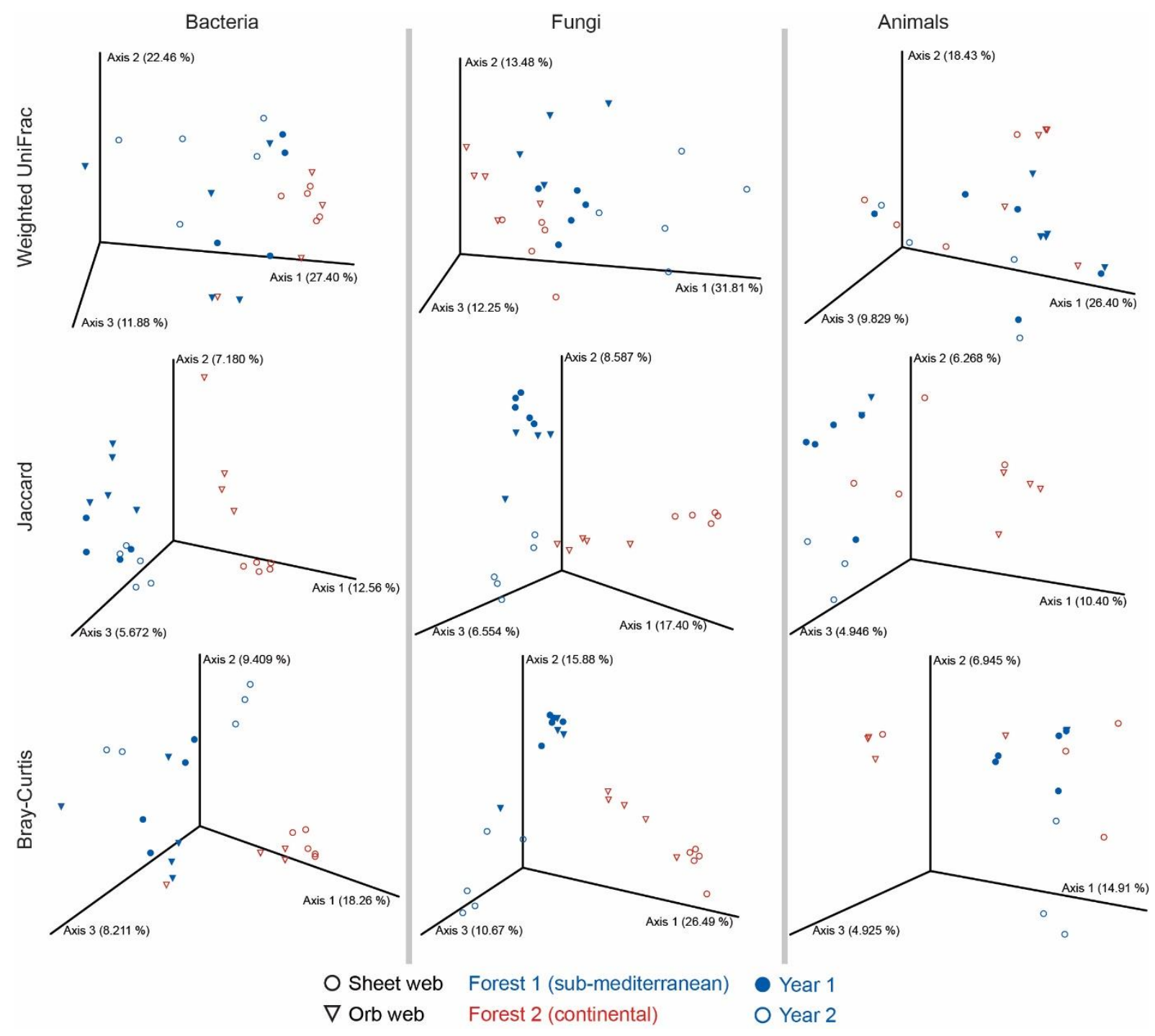

Figure 2: The beta diversities (community composition) of bacteria, fungi, and animals, inferred from spider web eDNA using a DNA metabarcoding approach. The PCoA plots visualize the beta diversities estimated using the weighted UniFrac distance metric, Jaccard index and the Bray-Curtis coefficient. 


\section{Animal taxa of interest}

Among animals, taxa of agricultural interest are perhaps the most common. We found several representatives of gall mites, family Eriophyidae (Trombidiformes). These are plant parasites, commonly causing galls and other damage to plant tissues ${ }^{1}$. Specifically, we found mites of the genus Abacarus, which includes the grain rust mite $A$. hystrix that lives on grass and can cause big loses in crop yields ${ }^{2}$, and the wheat curl mite Aceria tosichella that is a global cereal pest and a vector of viruses like wheat streak mosaic virus ${ }^{3}$. Within the family Phytoptidae (Trombidiformes), we found Nalepella brewerianae that is a parasite of Picea trees, and Phytoptus mites that induce galls on hazel trees ${ }^{4}$.

Among insects, all orders include agricultural pests and it is not surprising we found several in our samples. Among Diptera, we found the leaf miner fly Phytomyza crassiseta (family Agromyzidae) ${ }^{5}$, Delia flies (family Anthomyiidae) whose larvae cause agricultural losses by tunneling into roots and stems of host plants ${ }^{6}$, and several representatives of gall gnats (Cecidomyiidae) and fungus gnats (Sciaridae). Many species of gall gnats are important pests ${ }^{7}$, and recent studies even hint at a largely underestimated diversity of this family that could be one of the most species rich animal families in general ${ }^{8}$. Fungus gnats are mostly mushroom pests ${ }^{9}$.

Among Hemiptera, we found pine aphids (Pineus, Agelidae) that infest several pine species and can cause large economic damage ${ }^{10}$, whiteflies (Aleyrodes, Aleyrodidae) that are a major agriculture threat in greenhouses ${ }^{11}$, Aphrophora spittlebugs that can cause damage on trees with soft wood ${ }^{12}$, the Unaspis snow scales that are pests of spindle trees ${ }^{11}$, phylloxera (Phylloxeridae) that are pests of grapevines ${ }^{11}$, and aphids (Aphidae), e.g. the Anoecia aphids that are wheat and corn pests ${ }^{13}$, and the waxy grey pine needle aphid Schizolachnus pineti that infests pine plantations ${ }^{14}$. Some encountered taxa are plant disease vectors, e.g. many aphids are known virus vectors ${ }^{15}$, while some others, e.g. the privet leafhopper Fieberiella florii, transmit bacteria ${ }^{16}$.

Among other insect orders, the earwig Forficula auricularia (Forficulidae, Dermaptera) can cause significant damage to crops and fruit orchards ${ }^{17}$. We also found thrips (Thripidae, Thysanoptera), many of which are important agricultural pests ${ }^{17}$.

We found several taxa that are pollinators, e.g. the chironomid flies, the orange muscid fly Phaonia pallida, soldier flies (Stratiomyidae), several honeybee species (Apis, Apidae, Hymenoptera), the common wasp Vespula vulgaris (Vespidae, Hymenoptera), and butterflies and moths (Lepidoptera) ${ }^{18}$. We found one representative of long horn beetles (Cerambycidae, Coleoptera), where several endangered species belong to. Flies from the family Chironomidae were common in our samples. These occur in high numbers and play an important role in aquatic ecosystems. They are also important indicator organisms used for assessing water quality ${ }^{19}$.

We found several other interesting animal representatives. For example, most sheet web samples contained traces of freshwater rotifers from the class Bdelloidea. These microscopic animals live in different water bodies, in moist soil, and on mosses and lichens on tree trunks. During dry and harsh conditions, these rotifers enter a state of dormancy ${ }^{20,21}$. We hypothesize that rotifers in this state could have easily been carried around by wind and picked up by spider webs. We also found rhabditid nematodes (Nematoda, Rhabditida), a group consisting of mostly zooparasitic and phytoparasitic representatives ${ }^{22}$ that could have been transmitted to spider webs via their insect and plant hosts. Among Hexapoda, many web samples contained slender springtails (Collembola, Entomobryidae). These springtails are common in many habitats, including the canopy and other vegetation ${ }^{23}$. We identified no springtails exclusive to soil. 
bioRxiv preprint doi: https://doi.org/10.1101/2020.07.18.209999; this version posted July 19, 2020. The copyright holder for this preprin (which was not certified by peer review) is the author/funder, who has granted bioRxiv a license to display the preprint in perpetuity. It is made available under aCC-BY-NC-ND 4.0 International license.

Some taxa occurring in our samples indicate that eDNA from spider webs could be used to investigate species associations. For example, Scutacarus mites are associated with Lasius flavus ants $^{24}$, and Lasius ants commonly attend to nymphs of Anoecia aphids to obtain aphid honeydew ${ }^{25}$. All these taxa were present in our samples. Furthermore, using eDNA from spider webs, one could perhaps track parasitoid-host interactions. For example, we found Eulophidae, Ichneumonidae, Mymaridae, Platygastridae and Trichogrammatidae that are large families of parasitoid wasps, whose hosts comprise of a large range of arthropods ${ }^{11}$. Among these wasps, Polyaulon wasps are ant mimics and parasitoids ${ }^{26}$, and co-occurred with several ant species in our samples. Also, big-headed flies (Pipunculidae) almost exclusively parasitize leafhoppers ${ }^{27}$. Within a single web sample, we found the big-headed fly Clistoabdominalis and its potential cicadid hosts. Another example is the ant Solenopsis fugax that obtains food by klepto-parasitizing larger ant colonies ${ }^{28}$, and we found it cooccurring with four other ant species. 


\section{Fungal taxa of interest}

Several encountered families include representatives that are plant pathogens and thus important disease-causing agents of a large diversity of agricultural plants. Notable encountered examples include Fusarium, Gaeumannomyces, and Ustilago that damage barley and wheat $\operatorname{crops}^{29-31}$, Verticillium that damages hundreds of eudicot plants like cotton, tomatoes, potatoes, peppers, and eggplants ${ }^{32}$, the rice blast fungus Magnaporthe grisea that causes a serious rice disease ${ }^{33}$, and Armillaria that causes "white rot" root disease, mostly in trees and shrubs ${ }^{34}$.

Some encountered fungi are of potential human medical importance. We found several Cladosporum species that were present in most samples, and are one of the most common fungi isolated from air. Some species of this genus are human allergens that cause respiratory problems $\mathrm{s}^{35}$. Other taxa of potential medical importance were less common. Among these, Candida can cause infections in immunocompromised individuals ${ }^{36}$. Aspergillus representative can cause allergies and are important crop pests, whose mycotoxins can cause human diseases ${ }^{37}$. Cryptococcus neoformans sometimes causes meningo-encephalitis in immunocompromised individuals ${ }^{38}$. The black molds Stachybotrys are linked to damp environments and can cause respiratory problems and headaches ${ }^{39}$. Mucorales (phylum Mucoromycota) fungi can cause mucormycosis, a group of serious infections of the face, nose and mouth ${ }^{40}$. The gray fungus Botrytis can cause asthma, hay fever and keratomycosis ${ }^{41}$. Absidia are common soil fungi, and some cause food spoilage and pulmonary and gastrointestinal infections in immunocompromised individuals ${ }^{42}$. Bipolaris causes sinusitis, asthma, and hay fever ${ }^{43}$. Stachybotrys and Curvularia occur in forests, cause type I allergies (asthma, hay fever, sinusitis) ${ }^{44}$, while the latter can also cause pneumonia, corneal and nail infections ${ }^{39}$. Fusarium causes hay fever, asthma and keratitis ${ }^{45}$. Penicillium is common on moldy food and its ingestion is a significant health hazard ${ }^{44}$.

Some encountered representatives are used in human consumption. For example, mushrooms of the genera Agaricus are used directly for consumption, while Penicillium molds are used to ripen cheeses $^{46}$, and Saccharomyces fungi are used in, biofuel, baking, and beer and wine industry ${ }^{47}$. Beauveria bassiana and several species of Metarhizium are entomopathogenic fungi that are used as biological insecticides ${ }^{11,48}$. 
bioRxiv preprint doi: https://doi.org/10.1101/2020.07.18.209999; this version posted July 19, 2020. The copyright holder for this preprin (which was not certified by peer review) is the author/funder, who has granted bioRxiv a license to display the preprint in perpetuity. It is made available under aCC-BY-NC-ND 4.0 International license.

\section{Bacterial taxa of interest}

We encountered several bacteria that are potential agricultural pests as well as of medical importance to humans. For example, species of Rickettsia and Wolbachia are associated with a large variety of arthropod taxa, and are linked to both plant and human diseases ${ }^{49,50}$. We found several species of Acinetobacter, whose members are an important part of soil and water microbiomes ${ }^{51}$. Some species are human pathogens, and we encountered the potentially pathogenic $A$. ursingi $i^{52}$. Members of Staphylococcus are mostly harmless to humans, and occur in soil and on plant flowers ${ }^{53}$. Several species of Xanthomonas cause plant disease ${ }^{54,55}$. Salmonella occurs in the digestive tract and skin of warm and coldblooded animals, and is medically important for humans ${ }^{56}$. Salmonella and Clostridium, also encountered in our samples, can be present in flies and beetles, especially when collected around livestock ${ }^{57}$. Some species of Enterococcus cause human infections ${ }^{58}$. While some members of Haemophilus are important human pathogens, many have a range of hosts, and many are commonly found in invertebrate intestine ${ }^{56,59}$. Other genera with plant pathogenic representatives include Pseudomonas, Erwinia that typically infect woody plants, and Dickea and Pectobacterium that are mostly pathogens of herbaceous plants ${ }^{55}$. Pseudomonas pertucinogena produces pertucin, a bacteriocin active against the whooping cough causing Bordetella pertussis ${ }^{60}$. 


\section{References}

1 Hartford, H., Baker, E. W., Kono, T., Delfinado, M. \& Keifer, W. E. Illustrated guide to plant abnormalities caused by eriophyid mites in North America. (1982).

2 Skoracka, A. Quackgrass- and ryegrass-adapted populations of the cereal rust mite, Abacarus hystrix (Acari: Eriophyidae), differ in their potential for wheat, Triticum aestivum, colonization. Bull Entomol Res 99, 33-39 (2009).

3 Skare, J. M. et al. Colony establishment and maintenance of the eriophyid wheat curl mite Aceria tosichella for controlled transmission studies on a new virus-like pathogen. Journal of Virological Methods 108, 133-137 (2003).

4 Lindquist, E. E., Bruin, J. \& Sabelis, M. W. Eriophyoid mites: their biology, natural enemies and control. Vol. 6787 (Elsevier Science, 1996).

5 Spencer, K. A. Host specialization in the world Agromyzidae (Diptera). 444 (Kluwer Academic Publishers, 1990).

6 Chandler, P. J. Checklists of Insects of the British Isles (New Series) Part 1: Diptera. (Royal Entomological Society, 1998).

7 Gagné, R. J. A catalog of the Cecidomyiidae (Diptera) of the world. (Entomological Society of Washington, 2004).

8 Hebert, P. D. N. et al. Counting animal species with DNA barcodes: Canadian insects. 371, 20150333 (2016).

9 Scheepmaker, J. W. A., Geels, F. P., Smits, P. H. \& Van Griensven, L. J. L. D. Control of the mushroom pests Lycoriella auripila (Diptera: Sciaridae) and Megaselia halterata (Diptera: Phoridae) by Steinernema feltiae (Nematoda: Steinernematidae) in field experiments. 131, 359-368 (1997).

10 Day, R. K. et al. in Biological control in IPM systems in Africa (ed P. Neuenschwander, Borgemeister, C., Langewald, J.) 101-112 (2003).

11 Capinera, J. L. Encyclopedia of entomology. 2 edn, 4346 (Springer-Verlag New York Inc., 2008).

12 Hoch, $\mathrm{H}$. The leafhoppers and planthoppers of Germany (Hemiptera, Auchenorrhyncha): Patterns and strategies in a highly diverse group of phytophageous insects. 50, 259-260 (2003).

13 McGaving, G. C. Bugs of the world. (Facts on File, 1993).

14 Holopainen, J. K. \& Kainulainen, P. Reproductive capacity of the grey pine aphid and allocation response of Scots pine seedlings across temperature gradients: a test of hypotheses predicting outcomes of global warming. Canadian Journal of Forest Research 34, 94-102 (2004).

15 van Emden, H. F. \& Harrington, R. Aphids as crop pests. Vol. 2 (CABI, 2017).

16 Tedeschi, R. \& Alma, A. Fieberiella florii (Homoptera: Auchenorrhyncha) as a vector of "Candidatus Phytoplasma mali". 90, 284-290 (2006).

17 Capinera, J. L. Handbook of vegetable pests. (Elsevier Inc., 2001).

18 Faegri, K. \& Van der Pijl, L. Principles of pollination ecology. (Pergamon, 1979).

19 Walker, I. R. in Tracking environmental change using lake sediments. Volume 4: Zoological Indicators (eds J. P. Smol, H. J. B. Birks, \& W. M. Last) (Springer Netherlands, 2001).

20 Ricci, C. \& Melone, G. Key to the identification of the genera of bdelloid rotifers. Hydrobiologia 418, 73-80 (2000).

21 Örstan, A. Factors affecting long-term survival of dry bdelloid rotifers: a preliminary study. Hydrobiologia 387, 327-331 (1998).

22 Ley, P. D., Dorris, M. \& Blaxter, M. Patterns and processes in the evolution of animal parasitic nematodes. 2, 43 (2000).

23 Hopkin, S. P. Biology of the springtails (Insecta: Collembola). 340 (Oxford University Press, 1997). 
24 Khaustov, A. A. Myrmecophilous pygmephoroid mites (Acari: Pygmephoroidea) associated with Lasius flavus (Hymenoptera: Formicidae) in Russia. Zootaxa 4404, 345-370 (2015).

25 Depa, L. \& Wojciechowski, W. Ant-root aphid relations in different plant associations. Polish journal of entomology 77, 151-163 (2008).

26 Stigenberg, J., Boring, C. A. \& Ronquist, F. Phylogeny of the parasitic wasp subfamily Euphorinae (Braconidae) and evolution of its host preferences. 40, 570-591 (2015).

27 Koenig, D. P. \& Young, C. W. First observation of parasitic relations between big-headed flies, Nephrocerus Zetterstedt (Diptera: Pipunculidae) and crane flies, Tipula Linnaeus (Diptera: Tupulidae: Tipulinae), with larval and puparial descriptions for the genus Nephrocerus. Proceedings of the Entomological Society of Washington 109 (2007). Hölldobler, B. Chemische Strategie beim Nahrungserwerb der Diebsameise (Solenopsis fugax Latr.) und der Pharaoameise (Monomorium pharaonis L.). Oecologia 11, 371-380 (1973). Nelson, P. E., Dignani, M. C. \& Anaissie, E. J. Taxonomy, biology, and clinical aspects of Fusarium species. 7, 479-504 (1994).

30 Andrade, O. A., Mathre, D. E. \& Sands, D. C. Natural suppression of take-all disease of wheat in Montana soils. Plant and Soil 164, 9-18 (1994).

31 Kämper, J. et al. Insights from the genome of the biotrophic fungal plant pathogen Ustilago maydis. Nature 444, 97-101 (2006).

32 Barbara, D. J. \& Clewes, E. Plant pathogenic Verticillium species: how many of them are there? Molecular plant pathology 4, 297-305 (2003).

33 Talbot, N. J. On the trail of a cereal killer: Exploring the biology of Magnaporthe grisea. 57, 177-202 (2003).

34 Pegler, D. N. in Armillaria root rot: Biology and control of honey fungus (ed R. T. V. Fox) 8193 (2000).

35 Bensch, K., Braun, U., Groenewald, J. Z. \& Crous, P. W. The genus Cladosporium. Studies in mycology 72, 1-401 (2012).

36 Martins, N., Ferreira, I. C. F. R., Barros, L., Silva, S. \& Henriques, M. Candidiasis: Predisposing factors, prevention, diagnosis and alternative treatment. Mycopathologia 177, 223-240 (2014).

37 San-Blas, G. \& Calderone, R. A. Pathogenic fungi: Insights in molecular biology. 264 (Caister Academic Press, 2008).

38 Fan, W., Kraus, P. R., Boily, M.-J. \& Heitman, J. Cryptococcus neoformans gene expression during murine macrophage infection. 4, 1420-1433 (2005).

39 Andersen, B. et al. Molecular and phenotypic descriptions of Stachybotrys chlorohalonata sp. nov. and two chemotypes of Stachybotrys chartarum found in water-damaged buildings. Mycologia 95, 1227-1238 (2003).

40 Prabhu, R. M. \& Patel, R. Mucormycosis and entomophthoramycosis: a review of the clinical manifestations, diagnosis and treatment. Clinical Microbiology and Infection 10, 31-47 (2004).

41 Williamson, B., Tudzynski, B., Tudzynski, P. \& Van Kan, J. A. L. Botrytis cinerea: the cause of grey mould disease. 8, 561-580 (2007).

42 Hoffmann, K., Discher, S. \& Voigt, K. Revision of the genus Absidia (Mucorales, Zygomycetes) based on physiological, phylogenetic, and morphological characters; thermotolerant Absidia spp. form a coherent group, Mycocladiaceae fam. nov. Mycological Research 111, 1169-1183 (2007).

43 McGinnis, M. R., Rinaldi, M. G. \& Winn, R. E. Emerging agents of phaeohyphomycosis: pathogenic species of Bipolaris and Exserohilum. Journal of clinical microbiology 24, 250-259 (1986).

44 Kirk, P. M., Cannon, P. F., Minter, D. W. \& Stalpers, J. A. Dictionary of the Fungi. Vol. 10 (2010).

45 Ma, L.-J. et al. Fusarium pathogenomics. 67, 399-416 (2013). 
bioRxiv preprint doi: https://doi org/101101/2020 07.18.209999; this version posted July 19,2020 . The copyright holder for this preprin (which was not certified by peer review) is the author/funder, who has granted bioRxiv a license to display the preprint in perpetuity. It is made available under aCC-BY-NC-ND 4.0 International license.

46 Mrazek, J. et al. Effects of different strains Penicillium nalgiovense in the Nalzovy cheese during ripening. Journal of the science of food and agriculture 96, 2547-2554 (2016).

47 Ha, S.-J. et al. Engineered Saccharomyces cerevisiae capable of simultaneous cellobiose and xylose fermentation. 108, 504-509 (2011).

48 Barbarin, A. M., Jenkins, N. E., Rajotte, E. G. \& Thomas, M. B. A preliminary evaluation of the potential of Beauveria bassiana for bed bug control. Journal of Invertebrate Pathology 111, 82-85 (2012).

49 Perlman, S. J., Hunter, M. S. \& Zchori-Fein, E. The emerging diversity of Rickettsia. 273, 20972106 (2006).

50 Kozek, W. \& Rao, R. The discovery of Wolbachia in arthropods and nematodes - a historical perspective.

51 Horii, T., Tamai, K., Mitsui, M., Notake, S. \& Yanagisawa, H. Blood stream infections caused by Acinetobacter ursingii in an obstetrics ward. Infection, Genetics and Evolution 11, 52-56 (2011).

52 Doughari, H. J., Ndakidemi, P. A., Human, I. S. \& Benade, S. The ecology, biology and pathogenesis of Acinetobacter spp.: An overview. Microbes and Environments 26, 101-112 (2011).

53 Jacquemyn, H. et al. Among-population variation in microbial community structure in the floral nectar of the bee-pollinated forest herb Pulmonaria officinalis L. PLOS ONE 8, e56917 (2013).

54 An, S.-Q. et al. Mechanistic insights into host adaptation, virulence and epidemiology of the phytopathogen Xanthomonas. FEMS Microbiology Reviews 44, 1-32 (2019).

55 Mansfield, J. et al. Top 10 plant pathogenic bacteria in molecular plant pathology. 13, 614629 (2012).

56 Tortora, G. J., Funke, B. R. \& Case, C. L. Microbiology: an introduction. 13 edn, 960 (Pearson, 2020).

57 Wales, A. D. et al. Review of the carriage of zoonotic bacteria by arthropods, with special reference to Salmonella in mites, flies and litter beetles. 57, 299-314 (2010).

$58 \quad$ Ike, Y. Pathogenicity of Enterococci. Nihon saikingaku zasshi. Japanese journal of bacteriology 72, 189-211 (2017).

59 Ciancio, A. Invertebrate bacteriology: function, evolution and biological ties (sustainability in plant and crop protection). 349 (Springer, 2016).

60 Kawai, Y. Purification and characterization of pertucin produced by Pseudomonas pertucinogena. 6, 347-359 (1974). 